\title{
Tumor-Specific Catalysis-Mediated Enhanced Chemodynamic Therapy in Synergy with Mitophagy Inhibition Improves Therapeutic Efficacy in Endometrial Cancer
}

\author{
Xiaodi Gong \\ Shanghai Jiao Tong University School of Medicine \\ Jing Wang \\ Shanghai Jiao Tong University School of Medicine \\ Linlin Yang \\ Shanghai Jiao Tong University School of Medicine \\ Lijuan Li
}

Shanghai Jiao Tong University

\section{Xiao Sun}

Shanghai Jiao Tong University

Jingfeng Bai

Shanghai Jiao Tong University

Jichang Liu

East China University of Science and Technology

\section{Xin Pu}

East China University of Science and Technology

Yudong Wang ( $\nabla$ wangyudong@shsmu.edu.cn )

Shanghai Jiao Tong University

\section{Research}

Keywords: nanocatalyst, tumor microenvironment, chemodynamic therapy, mitophagy, Endometrial cancer

Posted Date: December 29th, 2021

DOI: https://doi.org/10.21203/rs.3.rs-1193131/v1

License: (9) (1) This work is licensed under a Creative Commons Attribution 4.0 International License. Read Full License 


\section{Abstract}

Background

Chemodynamic therapy (CDT) relies on tumor microenvironment (e.g. high $\mathrm{H}_{2} \mathrm{O}_{2}$ level) responsive Fenton-like reactions to produce hydroxyl radicals $(\cdot \mathrm{OH})$ against tumors. However, endogenous $\mathrm{H}_{2} \mathrm{O}_{2}$ is insufficient for effective chemodynamic reactions.

Results

An NAD $(P) H$ : quinone oxidoreductase $1(\mathrm{NQO1})^{\text {high }}$ Catalase $(C A T)^{\text {low }}$ therapeutic window for the use of NQ01 bioactive drug $\beta$-lapachone ( $\beta$-Lap) was firstly identified in endometrial cancer (EC). Accompanied by NADH depletion, $\beta$-Lap was catalyzed by NQO1 to produce excess $\mathrm{H}_{2} \mathrm{O}_{2}$ initiating oxidative stress, which selectively suppressed NQO1 ${ }^{\text {high }}$ EC cell proliferation, induced DNA double-strand breaks and promoted apoptosis. SiRNA-mediated NQO1 knockdown or dicoumarol rescued NQO1 ${ }^{\text {high }}$ EC cells from $\beta$ Lap-induced cytotoxicity. Arginine-glycine-aspartic acid (RGD)-functionalized iron-based metal organic frameworks-MOF $(\mathrm{Fe})$ further promoted the conversion of accumulated $\mathrm{H}_{2} \mathrm{O}_{2}$ into highly oxidative $\cdot \mathrm{OH}$, and in turn exacerbated the oxidative damage to RGD-positive target cells. Mitophagy inhibition by Mdivi1 blocked a powerful antioxidant defense approach, ultimately ensuring the antitumor efficacy of stepwise amplified ROS signals. The tumor growth inhibition rate was about $85.92 \%$.

Conclusions

Tumor specific chemotherapy in combination with CDT-triggered therapeutic modality presented unprecedented therapeutic advantages for the treatment of $\mathrm{NQO}^{+}$advanced type I or type II EC.

\section{Highlights}

- A therapeutic window for using $\beta$-lapachone for endometrial cancer was verified

- Initiating tumor in situ Fenton-like reaction achieves precise tumor therapy

- Inhibition of mitophagy can ensure the efficacy of chemodynamic therapy

\section{Introduction}

Endometrial cancer (EC) is the most common gynecological malignancy of female reproductive tract in developed countries. The incidence of EC is increasing by approximately $1 \%$ annually owing to the decreasing fertility rates and sustained weight gain [1]. Since the mid 1970's, survival for most cancers, with the exception of uterine cancer, have improved. The rise in mortality from uterine corpus cancer had speeded up from $0.3 \%$ per year (1997 2008) to $1.9 \%$ per year (2008 2018, twice the rate of increase in morbidity [2]. This suggests that the treatment for EC has encountered a bottleneck. Firstly, estrogen receptor (ER)/progesterone receptor (PR)-positive type I EC patients who initially had a favorable clinical 
response rate (68.0\%-85.3\%) to progesterone therapy developed acquired resistance (33.1-49.8\%), leading to disease recurrence and progression [[3], [4]]. What's more, there is an increasing number of type II EC (Estrogen-independent), who are insensitive to progesterone therapy and have poor prognosis, but lack of treatment regimens except hysterectomy [[5], [6]]. Therefore, new treatment strategies are urgently needed to explore for type II EC to improve therapeutic outcomes.

The highly reactive oxidation-containing chemical substances are collectively termed Reactive oxygen species (ROS), including singlet oxygen $\left({ }^{1} \mathrm{O}_{2}\right)$, superoxide radicals $\left(\mathrm{O}_{2}{ }^{--}\right)$, hydroxyl radicals $(\cdot \mathrm{OH})$, peroxides $\left(\mathrm{O}_{2}{ }^{2-}\right)$ and the hydrogen peroxide $\left(\mathrm{H}_{2} \mathrm{O}_{2}\right)$ [7]. Excessive ROS can activate high levels of oxidative stress and induce cytotoxicity by initiating the peroxidation of proteins, lipids, and DNA [8]. Therefore, ROS has been proved to enhance the efficacy of radiotherapy and chemotherapy, thus achieving synergistic anti-tumor effect [9]. In recent years, a variety of ROS generation nanoplatforms have been used in antineoplastic therapy. Notably, specific chemicals (e.g., low pH [10], elevated $\mathrm{H}_{2} \mathrm{O}_{2}$ level [11] and high reduced glutathione concentration [12]) in tumor microenvironment (TME) were used as endogenous stimuli to initiate in situ chemical reactions that convert non-toxic, tolerable chemicals into highly cytotoxic ROS for cancer therapy. This antitumor treatment modality was called CDT [13]. For example, iron-based nanomaterials such as $\mathrm{Fe}_{3} \mathrm{O}_{4}$ [[14], [15], [16], [17]], Iron oxide nanoparticles (IONPs) [18], $\operatorname{MOF}(\mathrm{Fe})$ [19]-mediated Fenton or Fenton-like catalysis reactions can convert intra-tumoral lowly reactive $\mathrm{H}_{2} \mathrm{O}_{2}$ to highly oxidative reactive $\cdot \mathrm{OH}$. Such an instantaneous in situ accumulation of excessive ROS will induce oxidative toxicity to tumor cells providing $\mathrm{H}_{2} \mathrm{O}_{2}$, but less damage to the normal tissues with low $\mathrm{H}_{2} \mathrm{O}_{2}$ level. Therefore, TME-specific CDT/CDT-involved combination treatment was proposed to be a promising regimen for antitumor therapy.

Although the concentration of $\mathrm{H}_{2} \mathrm{O}_{2}$ in the tumor regions is higher than that in normal tissues $(\sim 50-100$ $\mu \mathrm{mol} / \mathrm{L})$ [[20], [21]], which is not sufficient for effective chemical reactions [[22], [23]]. Therefore, it is necessary to introduce exogenous $\mathrm{H}_{2} \mathrm{O}_{2}$ releasing drugs or $\mathrm{H}_{2} \mathrm{O}_{2}$ precursors, or to reduce $\mathrm{H}_{2} \mathrm{O}_{2}$ scavenger to escalate intracellular $\mathrm{H}_{2} \mathrm{O}_{2}$ concentration. $\mathrm{NAD}(\mathrm{P}) \mathrm{H}$ : Quinone Oxidoreductase 1 (NQ01) is a twoelectron oxidoreductase that can convert most quinone (such as $\beta$-lapachone) to unstable hydroquinone using NADH or NADPH as a reduction cofactor [[24], [25]]. The hydroquinone species can be spontaneously oxidized by 2 dioxygen equivalents to produce superoxide. Generally, in 2 minutes 1 mole $\beta$-lapachone ( $\beta$-Lap, ARQ 501 or ARQ 761 in clinical form) is catalyzed by NQ01 to produce $~ 60$ moles of $\operatorname{NAD}(P)^{+}$forms and $\sim 120$ moles of superoxide, which is quickly transformed into $\mathrm{H}_{2} \mathrm{O}_{2}$, eventually causing oxidative damage to NQO1 ${ }^{\text {high }}$ tumor cells [26]. The expression of NQO1 is up to 5 200 fold higher in tumor tissues compared to the normal tissues, which is positively associated with advanced cancer stage, poorer prognosis, and lymph node metastasis [27]. As a tumor-specific NQ01-bioactivatable drug, $\beta$-Lap is currently undergoing clinical trials in patients with $\mathrm{NQO1}^{+}$solid tumors (ClinicalTrials.gov identifiersNCT02514031 and NCT01502800). 
Additionally, catalase (CAT) is a $\mathrm{H}_{2} \mathrm{O}_{2}$ eliminating enzyme capable of decomposing $\mathrm{H}_{2} \mathrm{O}_{2}$ to $\mathrm{H}_{2} \mathrm{O}$ and $\mathrm{O}_{2}$ and thereby mitigates $\mathrm{H}_{2} \mathrm{O}_{2}$-induced toxic effects [28]. Thus, tumors with $\mathrm{NQO}^{\text {high }} \mathrm{CAT}^{\text {low }}$ expression are considered as optimal candidates for $\beta$-Lap-dependent CDT. Even in adjacent tumor tissues with NQO1 $1^{\text {low }} C A T^{\text {low }}$ expression, high concentration of $\mathrm{H}_{2} \mathrm{O}_{2}$ can cause strong lethality through low CAT mediated bystander effect, without any effect on normal cells with $\mathrm{NQO}^{\text {low } C A T^{\text {high }}}$ expression.

Herein, we constructed a therapeutic system, in which NQO1 ${ }^{\text {high }}$ EC cell activated $\beta$-Lap combined with Fenton nanozyme mediated stepwise-enhanced CDT (Scheme 1). Firstly, in NQO1 ${ }^{\text {high }}$ EC cells, $\beta$-Lap exposure significantly upregulated intracellular $\mathrm{H}_{2} \mathrm{O}_{2}$ levels and $\mathrm{NAD}^{+} / \mathrm{NADH}$ ratio, triggering oxidative stress and inducing cell apoptosis. Furthermore, RGD functionalized nMIL-100(Fe) nanozyme catalyzed the conversion of accumulated $\mathrm{H}_{2} \mathrm{O}_{2}$ into highly reactive $\cdot \mathrm{OH}$, which further aggravated cellular oxidative damage leading to necrosis. Given that mitophagy was a barrier to $\mathrm{MOF}(\mathrm{Fe})$-catalyzed ROS-mediated anticancer strategies confirmed in previous studies [29]. Finally, pretreatment with Mdivi-1 (a mitophagy inhibitor) followed by the combination regimens of $\beta$-Lap and RGD-nMIL-100(Fe) yielded even more encouraging antitumor efficacy in vitro and in vivo, which were mainly manifested by the exacerbated ROS-induced apoptosis and aggravated growth inhibition.

\section{Results And Discussion}

\section{NQ01 ${ }^{\text {high }}{ }^{\text {CAT }}{ }^{\text {low }}$ provides a therapeutic window for utilizing of $\beta$-Lap in EC.}

In our previous study, it had been confirmed that nMIL-100(Fe) catalyzed exogenous $\mathrm{H}_{2} \mathrm{O}_{2}$ through Fenton-like reaction to produce $\cdot \mathrm{OH}$, which significantly inhibited the survival of KLE type II EC cells [29]. Lower expression of CAT (an enzymatic $\mathrm{H}_{2} \mathrm{O}_{2}$ scavenger) in KLE cells may be associated with high cell lethality, which forced cells being subjected to excessive ROS attack. In addition, since b-Lap was a NQ01-dependent bioactivatable drug, high expression of NQ01 was a prerequisite for b-Lap based antitumor therapy. Whether there was a NQO $1^{\text {high }} \mathrm{CAT}^{\text {low }}$ therapeutic window for b-Lap application to EC therapy. To probe this aspect, both NQO1 and CAT transcript levels were initially analyzed from TCGA database (https://tcga-data.nci.nih.gov/tcga/). Compared with normal tissues, NQ01 expression was obviously elevated accompanied by a decrease in CAT levels in tumor tissues, regardless of cancer individual stages and histological subtypes (Fig. 1a-c). Remarkably, low expression levels of CAT were strongly associated with the advanced clinical stages (Stage 4) and the histological subtype (Serous, type II EC) with poorer prognosis ( $p=5.76 \times 10^{-9}$ and $p=1.65 \times 10^{-12}$, respectively). From theses, we speculated that in this type of EC, there may be a vulnerability in the endogenous $\mathrm{H}_{2} \mathrm{O}_{2}$ scavenging mechanism dependent on CAT. In parallel, we also observed in Fig. $1 \mathrm{~d}$ the expression CAT was positively correlated with both ER and PR levels (Spearman R CAT/ER $=0.47, p=6.2 \times 10^{-11}$; Spearman $\mathrm{R}$ $\mathrm{CAT} / \mathrm{PR}=0.39, p=9.6 \times 10^{-8}$, respectively). The correlation between the expression of CAT and ER and / or PR further confirmed the above speculation by the fact that type II EC was mostly negative for ER and PR. The expression of NQ01 and CAT did not have direct carcinogenic or anti-cancer activity and were not 
significantly associated with overall survival in EC patients (Fig. 1e). Instead, as bioactive drug targets, they are involved in the anti-cancer strategy of regulating ROS: enhancing drug induction of ROS production ( $\mathrm{NQO}^{\text {high }}$ ) and inhibiting the antioxidant defense (CAT low) of tumor cells. Subsequently, to verify the existence of our TCGA database-based findings, we first assessed the expression status of NQ01 and CAT in tissue samples, and found that compared with normal endometrial tissues, there was such a treatment window for NQO1 ${ }^{\text {high }}$ CAT low in EC regardless of clinical stages (Fig. 1f). On top of evaluation in tissues, the levels of NQ01 and CAT were further validated in human EC cell lines including type I EC cells: well-differentiated Ishikawa $\left(\mathrm{ER}^{+} / \mathrm{PR}^{+}\right)$, intermediately-differentiated $\mathrm{HEC}-1 \mathrm{~A}\left(\mathrm{ER}^{ \pm} / \mathrm{PR}^{-}\right)$and HEC-1B (ER $\left.\pm / \mathrm{PR}^{ \pm}\right)$; poorly-differentiated AN3CA (ER//PR') and type II EC cells: KLE (ER/PR'). Human endometrial epithelial cells (EEC) were served as a normal cell control (Fig. 1g). The results showed such a high NQ01/CAT ratio was more prominent, especially in advanced EC tissue (II, III stages) and in KLE and AN3CA EC cells. Taken together, a NQO1 ${ }^{\text {high }}$ CAT low therapeutic window for the use of b-Lap had been found in EC, especially in the advanced type I and type II EC. These data provided a rationale for developing therapeutic strategies for $\beta$-Lap induced tumor-specific ROS production in these EC.

\section{$\beta$-Lap suppressed EC cell lines growth in an NQ01-dependent manner.}

Currently, b-Lap is undergoing clinical trials of monotherapy or combination therapy in patients with advanced NQO1 ${ }^{+}$solid tumors (linicalTrials.gov identifiers NCT02514031 and NCT01502800). However, there has been little discussion about the use of b-Lap in EC. Thus, we first validated EC cell lines with high expression of NQ01 (Ishikawa, AN3CA, HEC-1B and KLE) were more sensitive to $\beta$-Lap therapy (Fig. $2 a)$. That may be due to $\beta$-Lap-induced cell cycle arrest at the $\mathrm{G} 1$ phase, as confirmed by the concentration-dependent down-regulated Cyclin D1, c-Myc and upregulated P27 Kip1 levels (Fig. 2i). At concentrations of $8 \mathrm{mM}$ or higher, b-Lap significantly inhibited cell proliferation, even lead to cell lethality. While NQ01-absent normal human endometrial epithelial cells EEC and NQ01-low expressing 2 cervical cancer cell lines (HeLa and ME-180) (Additional file 1: Fig. S1), were resistant to $\beta$-Lap (Fig. 2a). Dicoumarol (DIC, an inhibitor of NQO1) spared NQ01 ${ }^{\text {high }}$ EC cells from b-Lap-induced lethality (Fig. 2b), partially recovered the colony-forming ability of KLE cells (Fig. $2 \mathrm{c}$ and Additional file 1: Fig. S2). One possible reason could be that b-Lap was not only an excellent substrate for NQ01, but also a wellcharacterized substrate for one-electron oxidoreductases (e.g. NADH: cytochrome b5 reductase, b5R), which simultaneously induced other one-electron redox reactions to further oxidize the biological macromolecules, such as DNA, RNA or proteins [21]. On top of that, the b-Lap enhanced-intracellular ROS levels restored to the observed baseline after DIC exposure (Fig. 2d). SiRNA-mediated knockdown of NQ01 deprived KLE cells sensitivity to $\beta$-lap exposure (Fig. 2e). While overexpressing NQ01 in HeLa cells endowed the susceptibility to $\beta$-Lap, and DIC reversed the effect of $\beta$-Lap on NQ01-overexpressed HeLa cells (Fig. 2f). Likewise, $\beta$-Lap significantly upregulated the ROS levels in NQ01-overexpressed HeLa cells and specific inhibition of NQ01 activity by DIC addition spared the above effect. Moreover, $\beta$-Lap induced KLE cells apoptosis in time- and concentration-dependent manner (Fig. 2h). Apoptosis marker protein cleaved Caspase-3 (cCaspase-3) and its cleaved product cleaved PARP (cPARP) were progressively accumulated $48 \mathrm{~h}$ after various concentrations $\beta$-Lap treatment (Fig. 2i). However, a lethal dose of $\beta$-Lap 
had been shown to induce "programmed necrosis" independent of caspase activation [30]. Thus, it is necessary to carry out another independent study to further reveal the correlation between the $\beta$-Lap lethality and caspase activation in EC. Then, $\mathrm{H}_{2} \mathrm{O}_{2}(500 \mathrm{mM}, 15 \mathrm{~min})$ served as a positive stimulus to induce DNA damage. Following different treatments annotated with 1-6 in Fig. $2 \mathrm{j}$ for $48 \mathrm{~h}$, the levels of phospho-histone H2A.X (Y-H2A.X) (Ser 139), an indicator of DNA double-strand breaks, were assayed by immunoblots and immunofluorescence, respectively. Similar to $\mathrm{H}_{2} \mathrm{O}_{2}$ exposure, $\mathrm{\gamma}-\mathrm{H} 2 \mathrm{~A}$.X expression was upregulated after $\beta$-Lap stimulation (group 2 vs group 5) compared with control or DIC treatment alone (group 1 and group 3). However, the salient difference was that $\beta$-Lap induced enhancement of $\mathrm{\gamma}-\mathrm{H} 2 \mathrm{~A}$.X expression could be eliminated by the NQO1 inhibitor-DIC, while the effect caused by $\mathrm{H}_{2} \mathrm{O}_{2}$ was not influenced by DIC (group 4 vs group 6). Given that NQ01 catalyzed $\beta$-Lap to incur a futile redox cycle, resulting in excessive $\mathrm{H}_{2} \mathrm{O}_{2}$ production and 2-fold consumption of NAD(P)H [26]. As displayed in Fig. 2k, $\beta$-Lap promoted the concentration-dependent release of $\mathrm{H}_{2} \mathrm{O}_{2}$ both in $\mathrm{KLE}$ and AN3CA cells only in short-term treatment, accompanied by a remarkable increase in intracellular $\mathrm{NAD}^{+} / \mathrm{NADH}$ ratio (Fig. 2l). Collectively, these data demonstrated that in vitro $\beta$-Lap induced $\mathrm{H}_{2} \mathrm{O}_{2}$ production and depleted intracellular NADH in an NQ01-dependent manner in EC cells. The elevated $\mathrm{H}_{2} \mathrm{O}_{2}$ caused extensive DNA double-strand breaks that induced a broad spectrum of DNA damage, which further stimulated hyperactivation of PARP to prevent massive DNA damage from repairing, leading to severe NAD+/ATP pool losses [[31], [32]]. These cumulative oxidative damage in turn triggered EC cell death referred to as "programmed necrosis" [33] or "necroptosis" [34], exclusive to the NQ01 bioactivatable drugs [35]. Could $\beta$-Lap be used as a monotherapy for patients with $\mathrm{NQO} 1^{+} \mathrm{EC}$, such as monoclonal antibodies and small molecules against typical targets (e.g. epidermal growth factor receptor: EGFR, vascular endothelial growth factor receptor: VEGFR)? Unfortunately, hemolytic anemia appeared as the primary dose-limiting toxicity (DLT) of prodrug of $\beta$-Lap during clinical trials, which was suspected to occur in almost all patients receiving high doses. Therefore, the maximum tolerated dose (MTD) of ARQ 501 and ARQ 761 had to be designed to $390 \mathrm{mg} / \mathrm{m}^{2}$ to alleviate the side effects. However, ARQ761 monotherapy was only moderately effective, leading to mild radiographic response in about $20 \%$ of patients, but no partial response [36]. Although the combination of $\beta$-Lap analogs and other chemodrugs such as PARP inhibitors [26], glutamine metabolism inhibitors [37], alkylating agents [38] and nicotinamide phosphoribosyl transferase inhibitors [39], exhibited superior synergistic antitumor effects in vitro and in vivo, the potential overlapping toxicity should be noted.

\section{Selective targeting in EC cells of Fenton-like catalyst RGD-nMIL-100(Fe)}

As mentioned above, due to dramatic $\mathrm{NAD}^{+}$depletion and ATP pool losses, NQ01-driven futile redox cycle may fail to function, resulting in an interruption of $\mathrm{H}_{2} \mathrm{O}_{2}$ output to the $\mathrm{EC}$ tumor site. Known from ROS electrochemistry, the most oxidizing one-electron oxidants (radical species, such as $\mathrm{O}_{2}{ }^{--}$and $\cdot \mathrm{OH}$ ) was $\cdot \mathrm{OH}$, which had a reduction potential $E^{O^{\prime}}\left(\cdot \mathrm{OH}, \mathrm{H}^{+} / \mathrm{H}_{2} \mathrm{O}\right)=2310 \mathrm{mV}$, obviously higher than $E^{O^{\prime}}\left(\mathrm{H}_{2} \mathrm{O}_{2}\right.$, $\left.\mathrm{H}^{+} / \mathrm{H}_{2} \mathrm{O}, \cdot \mathrm{OH}\right)=320 \mathrm{mV}$ [[7], [40]]. In addition, the reactivity of two-electron oxidants (nonradical species, such as $\mathrm{H}_{2} \mathrm{O}_{2}$ ) was determined by kinetic considerations. Due to the requirements for higher reaction 
activation energy and relatively slower reaction rate, $\mathrm{H}_{2} \mathrm{O}_{2}$ was actually only moderately reactive. Moreover, in clinical trials, $\beta$-Lap at therapeutic doses was associated with varying degrees of adverse effects, including anemia (79\%), fatigue (45\%), hypoxia (33\%), nausea (17\%), and vomiting (17\%) [36]. Encouragingly, $\beta$-Lap prodrugs prestored inside engineered micelles [41] and polymeric implants [42] enabled efficient intra-tumoral delivery and increased its tolerability. How could we reduce the dose of $\beta$ Lap without weakening oxidative stress it mediates? Therefore, the introduction of Fenton-like reagents into $\mathrm{NQO}^{+}$tumor sites could promote the reductive cleavage of excessive $\mathrm{H}_{2} \mathrm{O}_{2}$ induced by subtherapeutic dose $\beta$-Lap to highly reactive $\cdot \mathrm{OH}$, which would further up-regulate intracellular redox state to expand the oxidative damage. $\operatorname{MOF}(\mathrm{Fe})$ with high porosity, high specific surface area and abundant iron active centers were selected as Fenton-like nanocatalyst, which had been confirmed in our previous work [29]. RGD (arginine-glycine-aspartic) peptides offered high affinity for integrin aV $\beta 3$ receptor, which overexpressed on the surface of neovascularization and a broad variety of tumor cells [[43], [44], [45], [46]]. To increase cellular internalization, nanoscale MIL-100(Fe) (abbreviated as nMIL-100(Fe) below) was modified with FITC-labeled cyclic RGD motif to obtain CRGD-functionalized nMIL-100(Fe)s (RGDnMIL-100(Fe)) with tumor target ability (Fig 3a). Not only the morphologies (size and shape) of nMIL100(Fe) particles were not significantly altered before and after conjugation with CRGD (Fig 3b), but also the catalytic activities (Fig 3c-g). Fenton nanozyme effects of RGD-nMIL-100(Fe) particles were investigated using 2,2'-azino-bis(3-ethylbenzthiazdine-6)-sulfonic acid (ABTS) and 3,3',5,5' tetramethylbenzedine (TMB) as substrates. Compared with the particles or $\mathrm{H}_{2} \mathrm{O}_{2}$ alone, RGD-nMIL$100(\mathrm{Fe})$ could oxidize the two substrates separately into oxidized ABTS (oxABTS) and TMB (OxTMB) in the presence of $\mathrm{H}_{2} \mathrm{O}_{2}$, the maximum absorption peaks of which were at 500-900nm and $652 \mathrm{~nm}$ respectively (Fig. 3c, d). This data indirectly reflected $\mathrm{H}_{2} \mathrm{O}_{2}$ was converted into highly oxidative $\cdot \mathrm{OH}$ catalyzed by RGD-nMIL-100(Fe), as noted with nMIL-100(Fe) [29]. Furthermore, our nanocatalysts exerted RGD-nMIL-100(Fe) and $\mathrm{H}_{2} \mathrm{O}_{2}$ concentration-dependent catalytical activities (Fig. 3e, f). Besides, the generating of $\cdot \mathrm{OH}$ radicals with a shorter half-life $\left(10^{-9} \mathrm{~s}\right)$ was assessed by electron spin resonance (ESR) by adding 5,5-dimethyl-1-pyrroline-N-oxide (DMPO) as the radical trapping agent [47]. As presented in Figure $3 \mathrm{~g}$, the typical 1:2:2:1 spectra of DMPO/.OH adducts was only detected in the RGD-nMIL$100(\mathrm{Fe})+\mathrm{H}_{2} \mathrm{O}_{2}+\mathrm{DMPO}$ group, while no signal could be captured in RGD-nMIL-100(Fe)+DMPO, $\mathrm{H}_{2} \mathrm{O}_{2}+$ DMPO and the DMPO groups, proving the high catalytic capability of RGD-nMIL-100(Fe) for $\cdot \mathrm{OH}$ production. Then, in order to determine the optimal target cells for RGD-nMIL-100(Fe) nanoparticles, the obtained EC cells were analysed for integrin $\mathrm{aV}$ and $\beta 3$ level by immunoblots, using EEC as a negative control (Fig. 3h). The results revealed that both integrin $\mathrm{aV}$ and $\beta 3$ were significantly overexpressed in KLE, Ishikawa, AN3CA and HEC-1A cells, which were regarded as RGD-positive target cells. While RL95-2 and HEC-1B (expressing integrin aV only) were treated as RGD-negative target cells. Next, cellular internalization efficiency of RGD-nMIL-100(Fe) nanoparticles was measured by immunofluorescence. Pearson's correlation coefficient (Rr) and Manders' Overlap coefficient (M1) at the white solid line were calculated in the colocalization channel, by Image $\mathrm{J}$ software plug-in, Colocalization-Finder (scatter plots) and Plot Profile (line graphs). After incubation for $6 \mathrm{~h}$, the FITC-labeled nanoparticles (green spots) were found inside the KLE cells. This also reflected the successful modification of nanoparticles by free FITC 
or FITC-labeled RGD motif, because they didn't contain any fluorophore themselves, as shown in the control group (Fig. 3i). Most of these were scattered in the cytoplasm and almost completely overlapped with cytoskeletal protein-actin (red fluorescence, M1 $=0.95$ vs 0.98 , respectively), while a few entered the nuclei (blue fluorescence). Compared to nMIL-100(Fe), RGD-functionalized nMIL-100(Fe) nanoparticles achieved a high uptake rate of KLE cells ( $\mathrm{Rr}=0.50$ vs 0.12 , respectively). However, this discrepancy in internalization efficacy attributed to RGD modification was not as pronounced in RGD-negative targetHEC-1B cells as that observed in KLE cells, as shown in the bar graphs (Additional file 1: Fig. S3). Collectively, these data demonstrated that the successful modification of RGD peptides endowed Fenton nanocatalyst nMIL-100(Fe) with EC-targeting ability without compromising its catalytic performance, which set the stage for efficient cellular uptake of nanoparticles and their subsequent chemical catalysis.

\section{Amplified ROS signal combined with Mdivi-1 enhanced the anticancer effect of NQO1 ${ }^{\text {high }}$ EC cells}

Although the concentration of $\mathrm{H}_{2} \mathrm{O}_{2}$ in tumor sites $(\sim 50-100 \mu \mathrm{mol} / \mathrm{L})$ was higher than that in normal tissues, it was not sufficient for effective chemodynamic reactions [20]. Also, the aforementioned data had verified that $\beta$-Lap was a potent $\mathrm{H}_{2} \mathrm{O}_{2}$-generating agent in NQO1 ${ }^{\text {high }} \mathrm{EC}$. Hence, it is reasonable to speculate that massive $\mathrm{NQO1}$ initiated- $\mathrm{H}_{2} \mathrm{O}_{2}$ could be converted into highly oxidizing $\cdot \mathrm{OH}$ by the internalized RGD-MOF(Fe) mediated-Fenton reaction, resulting in step-wise amplified oxidative damage to NQO1 ${ }^{\text {high }}$ EC. Thus, RGD-positive target cells KLE (type II EC) and AN3CA (metastatic type I EC) of NQO1 $1^{\text {high }}$ CAT ${ }^{\text {low }}$ were selected as model cells to investigate the oxidative stress caused by $\beta$-Lapcombined with nMIL-100(Fe) nanoparticles. As shown in Fig 2a and 2i, $2.0 \mathrm{mM} \beta$-Lap had little effect on the growth of $\mathrm{NQO}^{\text {high }} \mathrm{EC}$ cells, while $25 \mathrm{mg} \mathrm{ml}^{-1} \mathrm{nMIL}-100(\mathrm{Fe})$ had the ability to catalyze $\mathrm{H}_{2} \mathrm{O}_{2}$ to generate $\cdot \mathrm{OH}$ (Fig 3e). To verify the " $1+1>2$ " combined effect, the dosage of nMIL-100(Fe) and $\beta$-Lap was reduced to $25 \mathrm{mg} \mathrm{ml}^{-1}$ and $2.0 \mathrm{mM}$, respectively. We first evaluated the mean fluorescence intensities (MFI) of DCFH-DA probe for intracellular ROS accumulation in response to the established exposures (Fig 4a). As expected, compared with $\mathrm{MOF}(\mathrm{Fe})$ nanoparticles or $\beta$-Lap treated alone groups and control groups, DCFH-DA fluorescence was brighter in the combined treatment group, especially in the RGD-nMIL$100(\mathrm{Fe})$ addition group. This indicated that in $\mathrm{NQO}{ }^{\text {high }} \mathrm{EC}$ cells, the co-treatment of MOF(Fe) nanoparticles and $\beta$-Lap could catalyze Fenton like-reaction to increase the production of intracellular ROS. The consistent results were further verified in cell viability assessment of both KLE and AN3CA cells (Fig 4b). Interestingly, the same dose of RGD-nMIL-100(Fe) alone appeared to achieve or even exceed the effect of nMIL-100(Fe) combined with subtherapeutic dose of $\beta$-Lap, while $50 \mathrm{mg} \mathrm{ml}^{-1}$ RGD-nMIL-100(Fe) combined group had the lowest proliferation inhibition rate. The possible reason was that due to higher internalization, the increased intracellular content and prolonged retention of RGD-nMIL-100(Fe) nanozyme in turn reduced the threshold of Fenton reaction in NQO1 ${ }^{\text {high }} \mathrm{EC}$ cells. This further elevated the efficiency of intracellular $\mathrm{H}_{2} \mathrm{O}_{2}$ conversion into $\cdot \mathrm{OH}$, whether $\mathrm{H}_{2} \mathrm{O}_{2}$ was endogenous or newly generated from NQ01-dependent futile redox cycles. Given that autophagy was a stumbling block in chemodynamic antitumor therapy involving MOF(Fe) [29]. Additionally, microtubule-associated protein 1 light chain 3B (LC3B)-II/LC3B-I ratio was significantly upregulated in $\beta$-Lap-treated KLE cells (Additional file 1: Fig. S4), 
suggesting $\beta$-Lap induced intracellular autophagy activation [48]. Coinciding with Mdivi-1 (a mitophagy inhibitor) would probably ensure better anticancer efficacy. Mdivi-1 addition (10 mM, $1 \mathrm{~h}$ ) first increased the percentage of both KLE and AN3CA cell proliferation repression in almost all treated groups. Albeit cell viability was slightly suppressed by Mdivi-1 pretreatment combined with non-lethal dose $\beta$-Lap $(1.0 \mathrm{mM})$. There was no overt difference between this combination arm and Mdivi- 1 alone group. This indicated that the inhibitory effect mainly attributed to autophagy block instead of $\beta$-Lap mediated oxidative stress. Additionally, both cell growth rates were the lowest when Mdivi-1, $\beta$-Lap and MOF(Fe) were present together, especially in the group containing RGD-nMIL-100(Fe) nanoparticles (Fig 4c). In line with the CCK-8 assays, the aforementioned combination of "Mdivi-1+RGD-nMIL-100(Fe)+ $\beta$-Lap" resulted in significantly more apoptosis in KLE cells, especially after $48 \mathrm{~h}$ of treatment (Fig 4d). Similarly, the Calcein AM probe staining indicated that compared with exposure to either solitary or any two treatments, RGD-nMIL-100(Fe) in combination with even $1.0 \mathrm{mM} \beta$-Lap significantly increased the relative proportion of cells with PI (red) staining for dead and apoptotic cells, aided by Mdivi-1 (Fig 4e). Besides, the expression of proliferation-related c-Myc and cyclinD1 were accordingly down-regulated; however, although caspase-3 remained activated, the substrate PARP, which was intended to repair broken DNA, was not reactively upregulated (Fig 4f). This was characteristic of "programmed necrosis" independent of caspase activation. As mentioned above, the anticancer strategy regulating intracellular ROS by "enhancing offense and weakening defense" was worth promoting in the treatment of type II EC.

\section{Investigation of synergistic antitumor effect in vivo}

Inspired by the excellent synergistic antitumor effects in vitro, we next assessed the anti-tumor efficacy and systemic toxicity of different treatments in vivo (Fig. 5a). The nude mice bearing KLE tumor were randomly divided into 5 groups: PBS, RGD-nMIL-100(Fe) (RM), $\beta$-Lap, RM+ $\beta$-Lap and Mdivi- $1+R M+\beta-$ Lap ( $n=5 /$ group). Compared to the PBS-treated mice, similar tumor growth was observed in the RM treated group (Fig. 5b), indicating that RM exposure alone had a negligible effect on tumor growth. Tumor growth was reduced in mice treated with $\beta$-Lap alone or $\mathrm{RM}+\beta$-Lap, with tumor growth inhibition (TGI) percentages of $41.19 \%$ and $46.25 \%$, respectively at endpoint. These two groups had suboptimal antitumor effects, which might be due to the low effective concentration of $\beta$-Lap at the tumor site and fast clearance in the blood stream. On the other hand, the NQ01-dependent $\cdot \mathrm{OH}$ mediated by RGD-nMIL$100(\mathrm{Fe})$ combining with $\beta$-Lap had a short half-life and also compensatively activated several antioxidant defense mechanisms. Excitingly, the TGI of the "Mdivi-1+RM+ $\beta$-Lap" group was $85.92 \%$, suggesting that this group-mediated therapy was more efficient than free RM or $\beta$-Lap or RM+ $\beta$-Lap, which could be explained by prior blockade of self-antioxidant defense modulation-mitophagy and subsequent stepwise increasing oxidation intensity arising from the increased cellular internalization capability and highly efficient Fenton-like reaction of RM nanoparticles. Meanwhile, no differences in body weight were observed among each group (Fig. 5c). Tumor weight of all the treatment groups were measured at the experiment endpoint (day 17) from euthanized mice, agreeing well with the aforementioned tumor volume results. The minimal tumor weight was formed in the "Mdivi- $1+R M+\beta$-Lap" -treated group, demonstrating again that the highest tumor inhibition ratio in this group (Fig. $5 d$ and Additional file 1: Fig. S5). The above results firmly investigated that the anti-tumor efficacy of combined therapy with $\mathrm{RM}+\beta-$ 
Lap-mediated CDT and mitophagy inhibition by Mdivi-1 was remarkable. As illustrated in Fig. 5e, immunohistochemical (IHC) staining of KLE tumor sections from the mice received monotherapy (RM: RGD-nMIL-100(Fe) and $\beta$-Lap) or combination therapy (RM+ $\beta$-Lap) displayed that Parkin (brown), a key protein in activated PINK1/Parkin mitophagy pathway, was variably upregulated in comparison to PBS-treated group. These enhanced CDT could trigger cellular protective mitophagy effect to varying extent, as noted in our previous study [29]. Pretreatment with Mdivi-1 (10mg/kg) markedly suppressed the expression of Parkin, which might be responsible for the higher anti-tumor efficacy of the Mdivi- $1+\mathrm{RM}+\beta-$ Lap administrations. Additionally, the Ki-67 IHC and staining transferase-mediated dUTP nick endlabeling (TUNEL) assays were used to further detect the proliferation and apoptosis of KLE xenograft tumors, respectively. The lowest proliferating cells (brown) and the most apoptotic cells (green) were observed in the Mdivi-1+RM+ $\beta$-Lap group. This revealed that anticancer efficacy was due to reduced cell proliferation and aggravated cell apoptosis. Notwithstanding, haematoxylin and eosin (H\&E) staining showed no obvious signs of morphological changes or tissue damages in the heart, liver, spleen, lung and kidney of mice after 17 days of different treatments (Fig. 5f). As well, the corresponding blood biochemical indexes were in the normal ranges (Additional file 1: Fig. S6). The above results suggested that NQ01-dependent Fenton nano-catalyst initiated-CDT combined with Mdivi-1 mediated mitophagy blockade exerted convincing synergistic antitumor effects without organ toxicity in type II EC.

In summary, these insights offered additional therapeutic avenues for EC patients, especially for those with refractory EC (e.g. type II EC, advanced, recurrent, or persistent EC) and with demands for fertilitysparing. We reported for the first time there was a NQ01 ${ }^{\text {high }} \mathrm{CA}{ }^{\text {low }}$ therapeutic window in EC for the use of $\beta$-Lap, the clinical forms of which (ARQ 501 or ARQ 761) were being tested in clinical trials in other $\mathrm{NQO}^{+}$tumors (ClinicalTrials.gov identifiers NCT02514031 and NCT01502800). In vitro $\beta$-Lap exerted selectively antineoplastic activity by NQ01 mediated-EC cell lethality, but no killing effect on NQ01 normal cells. Taking into account the prominent dose-limiting toxicity (DLT) of $\beta$-Lap analogues in clinical trials, we found a shortcut to reduce the amount of $\beta$-Lap without weakening its mediated oxidative stress as follows: RGD-functionalized Fenton nanocatalyst-nMIL-100(Fe) was introduced to catalyze the decomposition of intracellular accumulated $\mathrm{H}_{2} \mathrm{O}_{2}$ (including intrinsic and the newly produced by NQO1catalyzed nonlethal dose of $\beta$-Lap) into higher oxidative activity $\cdot \mathrm{OH}$. Such a process from an increase in the abundance of $\mathrm{ROS}\left(\mathrm{H}_{2} \mathrm{O}_{2}\right.$ levels) to escalation in oxidation intensity $(\cdot \mathrm{OH}$ generation) stepwise amplified the oxidation signals released by NQ01+ cells. In turn, the enhanced intracellular "oxidative attack" broke the original redox equilibrium within the TME to exert greater cytotoxic effects on both $\mathrm{NQO}^{+}$and neighboring NQ01- EC cells via a bystander effect. Lastly, based on our previous findings, the addition of Mdivi-1 spared mitophagy-initiated "antioxidant defense". Taken together, our current data highlights the combination of nonlethal dose of $\beta$-Lap plus nMIL-100(Fe) with Mdivi-1 pretreatment represented an encouraging synergistic anticancer effect of " $1+1+1>3$ ".

Nevertheless, the present work did have potential limitations. As a preliminary exploration of EC therapy, the blood circulation of RGD-nMIL-100(Fe) nanoparticles hadn't been taken into account. Thus, only local intra-tumoral injection was performed for different formulations in vivo. Besides, although RGD-modified

Page 10/29 
nMIL-100(Fe) had a satisfactory targeting effect at the cellular level, the ability of its active targeting tumor tissue still needed to be further warranted in vivo. Thirdly, there was a lack of more precise quantitative analysis methods such as Chou-Talalay to evaluate the synergistic effect of drug combination, so as to provide a more accurate reference for guiding rational drug use in the follow-up. Despite its exploratory nature, this study offered some valuable insights into the establishment of effective treatment strategies for refractory or special types of EC.

\section{Conclusion}

To sum up, the findings of this research have provided insights for how $\beta$-Lap, a NQ01 bioactive prodrug, selectively targets EC cells and exerts antineoplastic activity without affecting normal cells, and how $\beta$ Lap, as an exogenous source of $\mathrm{H}_{2} \mathrm{O}_{2}$, favors specific in situ Fenton-like reactions driven by MOF(Fe) only in tumor to display a higher therapeutic efficiency through highly oxidative toxic $\cdot \mathrm{OH}$ with negligible side effect. Aided by antioxidant-inhibition, tumor-specific ROS-inducing strategy forms a complete closed loop therapy. Overall, as-constructed combined system of nanomedicine and chemotherapy represented a promising therapeutic avenue against EC regardless of tumor type.

\section{Materials And Methods}

\section{Chemicals}

Iron (III) chloride hexahydrate $\left(\mathrm{FeCl}_{3} \cdot 6 \mathrm{H}_{2} \mathrm{O}, \mathrm{AR}\right)$ and 1,3,5-Benzenetricarboxylic acid (H3BTC, 99\%) were purchased from Aladdin (Shanghai, China). Mdivi-1 and b-Lapachone were from MedChemExpress. Nhydroxysuccinimide (NHS), 1-ethyl-3-(3-(dimethylamino) propyl) carbodiimide hydrochloride (EDC), Fluorescein isothiocyanate, Isomer I (FITC) (A642107-0500), Cyclo(RGDfK(K(FITC) peptide (purity at $>95 \%$ ) was provided by Apeptide Bio-Technology (Shanghai, China). Anti-rabbit IgG, HRP-linked antibody (\#7074S), anti-mouse IgG, HRP-linked antibody (\#7076S), anti-Cleaved Caspase-3 (9662S), anti-Cleaved PARP (5625T), anti-c-Myc (\#5605), anti-Cyclin D1 (\#55506), anti-Integrin aV (\#4711) and anti-Integrin $\beta 3$ (\#13166) were from Cell Signaling Technology. Rabbit anti-Catalase (R23734), mouse anti-NQ01 (220638), mouse anti-Phospho-Histone H2A.X(Ser139) (201082-7G9) and Rabbit anti-Parkin (381626) were purchased from Zen BioScience (Chengdu, China). HRP-conjugated mouse anti-GAPDH (\#30203ES10) and HRP-conjugated anti- $\beta$-Tubulin (30303ES10) were provided by Yeasen Biotech (Shanghai, China).

\section{Preparation and Characterization}

$484 \mathrm{mg}$ of iron (III) nitrate nonahydrate and $210 \mathrm{mg} \mathrm{1,3,5-benzenetricarboxylic} \mathrm{acid} \mathrm{were} \mathrm{dissolved} \mathrm{in}$ deionized water ( $\mathrm{DI}, 5 \mathrm{~mL}$ ) followed by stirring. The mixture was then turned to a Telfon-lined stainlesssteel autoclave. The autoclave was closed and kept at $180^{\circ} \mathrm{C}$ for $12 \mathrm{~h}$. Subsequently, let cool naturally to room temperature (RT). The obtained precipitates by filtration were rinsed with methanol for 3 times. The yellow nMIL-100(Fe) was collected and dried in a vacuum oven at $60^{\circ} \mathrm{C}$ for $12 \mathrm{~h}$. 
Cyclo(RGDfK(K(FITC) peptide was connected to the carboxylic groups of nMIL-100(Fe) through EDC/NHS chemistry. Briefly, NHS $(8.65 \mathrm{mg})$ and EDC $(14.41 \mathrm{mg})$ were mixed with a dimethylsulfoxide (DMSO) solution of nMIL-100(Fe) $(5 \mathrm{~mL}, 2 \mathrm{mg} / \mathrm{mL})$. The obtained solution was stirred at RT for $4 \mathrm{~h}$ in the dark. The activated nMIL-100(Fe) nanoparticles (NPs) were collected by centrifuging at $13000 \mathrm{rpm}$ for $10 \mathrm{~min}$ and rinsed in DI to remove residual EDC and NHS. Cyclo(RGDfK(K(FITC) peptide was dissolved in phosphate-buffered saline (PBS, $\mathrm{pH}=7.4$ \solution at $1 \mathrm{mg} / \mathrm{mL}$ concentration. The recovered particles were redispersed into above solution and stirred in the dark overnight. The RGD-nMIL-100(Fe) were collected by centrifuging $(13,000 \mathrm{rpm}, 10 \mathrm{~min})$ and washed with $\mathrm{DI}$ at least three times. The obtained precipitates was redispersed into PBS and stored at $4{ }^{\circ} \mathrm{C}$.

Transmission electron microscopy (TEM) assays were carried out on a high-resolution JEM-2100 microscope (JEM Ltd., Japan). The UV-vis spectrophotometer (Varian Cary 500) was used for the measurement of absorbance.

\section{Catalytic activity}

To assess the oxidative ABTS and TMB, absorbance was determined after different experimental conditions including various doses of $\mathrm{H}_{2} \mathrm{O}_{2}(25,50$, and $100 \mu \mathrm{M}), \mathrm{RGD}-\mathrm{nMIL}-100(\mathrm{Fe})(25,50$ and 100 $\mu \mathrm{g} / \mathrm{mL}$ ) as well. The absorption peaks of solution with $50 \mathrm{mM} \mathrm{H}_{2} \mathrm{O}_{2}$ and $100 \mu \mathrm{g} / \mathrm{mL} \mathrm{nMIL-100(Fe)} \mathrm{were}$ used as positive control.

\section{ESR detection}

DMPO (20 mM) was added into aqueous solution with $100 \mu \mathrm{g} / \mathrm{mL}$ nMIL-100(Fe)/RGD-nMIL-100(Fe) and $50 \mu \mathrm{M} \mathrm{H}_{2} \mathrm{O}_{2}$ at RT. The resulting product was quickly moved into a quartz capillary tube. The ESR spectra was recognized on a Bruker EMX-8/2.7 Electro-Spin Resonance Spectrometer.

\section{Cell lines and culture}

HEC-1A and ME-180 cells (McCoy's 5a Medium Modified, HyClone), Ishikawa and KLE cells (Dulbecco's Modified Eagle Medium/Nutrient Mixture F-12 medium, HyClone), HEC-1B, AN3CA and SiHa cells (Eagle's Minimum Essential Medium, HyClone) and Ca Ski, HeLa cells (RPMI 1640 Medium, Gibco) were obtained from the American Type Culture Collection (ATCC) and supplemented with $10 \%$ FBS, $1 \%$ penicillin and streptomycin at $37^{\circ} \mathrm{C}$ in a $5 \% \mathrm{CO}_{2}$ atmosphere.

Human endometrial epithelial cell (EEC, Epithelial Cell Medium, ScienCell) was provided by Mingzhou Biotechnology (Ningbo, China). Specially, 2\% FBS and 1\% epithelial cell growth supplement needed to be added into medium.

\section{Cell uptake}

To evaluate the extent of nanoparticles internalization, $2 \times 10^{5}$ cells well $^{-1} \mathrm{KLE}$ and HEC-1B cells were cultured in 6-well plates overnight. 100 gg/mL FITC-nMIL-100(Fe) or FITC-RGD-nMIL-100(Fe) was 
added and incubated for $6 \mathrm{~h}$ and then rinsed cells with PBS ( $\mathrm{pH}=7.4)$ for three more times. Cells were stained with Actin-Tracker Red-594 dye (Beyotime Biotechnology) in the dark for 30 min at $37^{\circ} \mathrm{C}$. After that, culture supernatant was removed and followed by PBS washing for three times. Finally, cellular nuclei were labeled by Hoechst 33342 (Yeasen Biotech) for 5 min (protect from light). Subsequently, every well was immediately analyzed by a FV1000 confocal fluorescence microscope. The intensity and localizations of red/green fluorescence were determined by the ImageJ 1.8.0 (USA) software.

\section{NQ01 knockout and overexpression.}

Human NQ01 gene in KLE cells was knocked down by siRNA transfection. Negative control siRNA (NC) and siRNA against NQ01-1, -2,-3 (siRNA1, siRNA2 and siRNA3) were purchased from OBiO Technology (Shanghai). The plasmid was transiently transfected into KLE cells by Lipofectamine ${ }^{T M} 3000$ (Invitrogen, USA). 48h after transfection, cells were harvested for assessment of NQ01 expression by western blotting assay. KLE cells transfected with NQ01 siRNA-1 were used for following cell viability assay.

For NQ01 overexpression, HeLa cells (NQO1 null) were transiently transfected with a human pcDNANQ01 (OBiO Technology) by Lipofectamine ${ }^{\mathrm{TM}} 3000.48 \mathrm{~h}$ later, transfection efficiency was assessed by western blotting. HeLa cells transfected with pcDNA-NQ01 were treated by b-Lap with or without $10 \mu \mathrm{M}$ DIC for $4 \mathrm{~h}$. Then, cell viability and intracellular ROS level were detected as follows.

\section{Cell viability assays}

To determine cell viability using Cell Counting Kit-8 (CCK8; Dojindo Laboratories, Japan), $5 \times 10^{3}$ cells / well were cultured in 96-well plate supplemented 200 ul complete medium overnight. Then the media were changed with $200 \mu \mathrm{L}$ of fresh, different drug formulations-containing medium according to per established protocols. After that, cells were washed twice with PBS and further cultured for up to $48 \mathrm{~h}$ in $5 \% \mathrm{CO}_{2}$ at $37^{\circ} \mathrm{C} .100 \mu \mathrm{L}$ medium containing $10 \%$ CCK-8 solution was added into each well and cells were continually cultured for $1 \mathrm{~h}$. The absorbance was tested at $450 \mathrm{~nm}$ using a microplate reader (EL800, BioTek Instrument, USA).

Moreover, to identify colony-forming ability, KLE (500 cells/well) were grown in six-well plates overnight. ( 0 to $8 \mu \mathrm{M}$ ) $\beta$-Lap with or without $10 \mu \mathrm{M}$ DIC were introduced into cells for $4 \mathrm{~h}$ and then fresh medium was replaced every $48 \mathrm{~h}$. After 14 days, cells were fixed with $4 \%$ paraformaldehyde for $15 \mathrm{~min}$ at RT, stained with $0.5 \%$ crystal violet stain solution (Yeasen Biotech, Shanghai) for $30 \mathrm{~min}$, and counted and photographed by a digital camera.

Besides, cell cytotoxicity was also analyzed by Calcein AM Cell Viability Assay Kit. In brief, cells were subjected to variousexposures as established protocols for $48 \mathrm{~h}$ and washed with PBS for twice. Calcein AM working buffer was added into cells for $30 \mathrm{~min}$ at $37^{\circ} \mathrm{C}$ and then Propidium lodide (PI) stained them for $15 \mathrm{~min}$ (protect from light). Finally, every well was observed by a fluorescence microscope (Leica DMIL, Germany). Image J 1.8.0 (USA) software was used to count the number of red/green fluorescence. 


\section{Cell apoptosis analysis}

Apoptotic cells analysis was performed via Annexin V-FITC/PI Apoptosis Detection Kit (Yeasen Biotech, \#40302ES20) according to the manufacturer's protocol. In brief, KLE cells were treated by different concentrations b-Lap ( 0 to $8 \mathrm{mM}, 4 \mathrm{~h}$ ) and continued to culture for up to $24 \mathrm{~h}$ or $48 \mathrm{~h}$. Cell suspension was harvest and mixed with $5 \mu \mathrm{L}$ Annexin V-FITC and $10 \mu \mathrm{L} \mathrm{PI} \mathrm{gently} \mathrm{in} \mathrm{the} \mathrm{dark} \mathrm{at} \mathrm{RT.} \mathrm{The} \mathrm{prepared}$ specimen need to be analyzed by flow cytometry (BD Biosciences) within $1 \mathrm{~h}$.

\section{ROS assay}

Firstly, ROS was determined with a 2', 7'-dichlorofluorescein diacetate (DCFH-DA)-ROS Assay Kit (Beyotime Biotechnology). $2 \times 10^{5}$ /well cells were seeded in 6-well plates respectively. Afterward, cells were stained with $10 \mu \mathrm{M}$ DCFH-DA probe at $37^{\circ} \mathrm{C}$ for $30 \mathrm{~min}$, then washed with serum free media three times. Then, cells were added with different concentration of $\beta$-lap with or without DIC or combined with $100 \mu \mathrm{g} / \mathrm{mL}$ MOF(Fe) nanoparticles or $10 \mu \mathrm{M}$ Mdivi-1 or both all for $4 \mathrm{~h}$. ROS signals was detected by Flow cytometry (BD Biosciences) at Ex/Em: 485/525 nm. The mean fluorescence intensities (MFI) were evaluated by the Image $\mathrm{J} 1.8 .0$ (USA) software.

Besides, the $\mathrm{H}_{2} \mathrm{O}_{2}$ release of $\beta$-lap-treated KLE and AN3CA cells were detected by Hydrogen Peroxide Assay Kit (Colorimetric Fluorometric) (Abcam, Ab102500). According to the manufacturer's protocol, $2 \times$ $10^{6}$ cells were collected and resuspend in $500 \mu \mathrm{L}$ Assay Buffer on ice, and then homogenized and centrifuged $\left(13,000 \mathrm{~g}, 5 \mathrm{~min}\right.$, at $\left.4^{\circ} \mathrm{C}\right)$. The supernatant was recovered and deproteinized as instruction described. $50 \mu \mathrm{L}$ the above specimen incubated with $50 \mu \mathrm{L}$ Reaction Mix for 10 min protected from light at RT. The output of $\mathrm{H}_{2} \mathrm{O}_{2}$ was measured at OD $570 \mathrm{~nm}$ on a microplate reader (EL800, Bio-Tek Instrument, USA).

\section{Immunoblotting}

For basic expression of NQ01, CAT, Integrin aV and Integrin $\beta 3$, all humancervical cancer cells, human endometrial cancer cells and EEC were collected at a density of $1 \times 10^{7}$ cells. For the effect of ROS on cell growth, KLE cells treated by different concentration of b-Lap with or without $10 \mu \mathrm{M}$ DIC and different combinations with b-Lap with $100 \mu \mathrm{g} / \mathrm{mL}$ nMIL-100(Fe) or RGD-nMIL-100(Fe) or Mdivi-1 $\left(10 \times 10^{-6} \mathrm{M}, 1 \mathrm{~h}\right.$ ) pretreatment for $48 \mathrm{~h}$. Afterward, cells lysates were obtained by RIPA lysis buffer. Protein samples were isolated by sodium dodecyl sulfate-polyacrylamide gel electrophoresis (SDS-PAGE, $12.5 \%$ or $10 \%$ ) and then transferred onto nitrocellulose (NC, Millipore) membranes $(0.45 \mu \mathrm{m}$ pore size). Subsequently, NC membranes were blocked with 5\% BSA in Tris-buffered saline with $0.1 \%$ Tween-20 (TBST) for $2 \mathrm{~h}$ at RT and further incubated with primary antibodies sequentially including anti-CPARP anti-NQ01, anti-CAT, antiIntegrin aV, anti-Integrin $\beta 3$, anti-cMyc, anti-Cyclin D1, anti-cCaspase-3 and HRP-conjugated anti-GAPDH $(1: 1,000)$ at $4{ }^{\circ} \mathrm{C}$ overnight. After rinsing three times with TBST for 5 min each on the shaker, the membranes were incubated with secondary antibodies $(1: 5,000)$ for $45 \mathrm{~min}$ at RT. The protein bands were developed with chemiluminescence (Millipore \#P90720, USA) reagent on an Image Quant LAS4000 
system (GE Healthcare), and were normalized to $\beta$-Tubulin or GAPDH signal and further semi-quantified by the ImageJ 1.8.0 (USA) software.

\section{Y-H2A.X assay}

To determine the Phospho-Histone H2A.X (Ser139) expression of KLE cells treated by different exposures including: PBS (control); $\beta$-Lap (8 mM, 4 h); DIC (10 $\mu \mathrm{M}, 4$ h); $\beta$-Lap (8 mM, 4 h) + DIC (10 $\mu \mathrm{M}, 4 \mathrm{~h})$; $\mathrm{H}_{2} \mathrm{O}_{2}(500 \mathrm{mM}, 15 \mathrm{~min}) ; \mathrm{H}_{2} \mathrm{O}_{2}(500 \mathrm{mM}, 15 \mathrm{~min})+\mathrm{DIC}(10 \mathrm{mM}, 15 \mathrm{~min})$, immunoblots were performed as described above. Also, immunofluorescence staining of KLE cells was conducted as follows. After fixing in pre-cooled methanol/acetone (7:3) mixture for $10 \mathrm{~min}$, cells were rinsed with PBS twice for 5 min, and blocked with QuickBlock ${ }^{\text {TM }}$ Blocking Buffer (Beyotime Biotechnology, P0260) for 30 min. Phospho-Histone H2A.X (Ser139) antibody (1:200 dilution) was incubated at $4{ }^{\circ} \mathrm{C}$ overnight and the Alexa Fluor 488 secondary antibody (1:1000, Jackson ImmunoResearch, 115-545-003) at RT for $1 \mathrm{~h}$. Finally, Fluorescence images were observed by fluorescence microscopy.

\section{Tumor models}

Five-week-old female BALB/c nude mice were purchased from Shanghai SLAC Laboratory Animal Co., Ltd. Medical Sciences and maintained in a pathogen-free environment. Animal care and experiments were performed in according with the guidelines approved by the Animal Ethics Committee of International Peace Maternity and Child Health Hospital, Shanghai Jiao Tong University School of Medicine (Shanghai, China). KLE tumor tissues from congenic mice were dissected into $\sim 1 \mathrm{~mm}^{3}$ nearly round tissue blocks and then subcutaneously implanted in the right armpit. When the tumors grew to $\sim 100 \mathrm{~mm}^{3}$, this day set as day 0 (D0) and intra-tumoral injection of different formulations was conducted. The tumor volume was calculated by the formula: volume $=$ length $\times$ width $^{2} / 2$.

\section{In vivo antitumor therapeutic efficacy}

The mice were randomly divided into 5 treatment groups $(n=5)$. were randomly divided into 5 groups: PBS, RGD-nMIL-100(Fe) (RM), $\beta$-Lap, RM+ $\beta$-Lap and Mdivi-1+RM+ $\beta$-Lap ( $n=5 /$ group). The dosage of $\beta$ Lap, Mdivi-1 and RM was $5 \mathrm{mg} \mathrm{kg}^{-1}, 10 \mathrm{mg} \mathrm{kg}^{-1}$ and $5 \mathrm{mg} \mathrm{kg}^{-1}$ in these formulations, respectively. Mdivi-1 in Group 5 (Mdivi-1+RM+ $\beta$-Lap) was administered intra-tumoral once every 2 days for total of 4 doses starting at Day 1 (D1), while other treatments from Group1-4 and RM+ $\beta$-Lap in Group 5 were intratumorally injected from D2 for a total of four times. Tumor volume and body weight were measured and recorded every 3 days. At D17 post treatment mice were euthanized, tumors and major organs were excised, and tumor weight was also measured.

\section{Tissue pathology assessment}

For the assessment of tissue pathology, major organs (heart, liver, spleen, lung and kidney) and tumor tissues were extracted fixed in paraformaldehyde $(4 \%)$ for $24 \mathrm{~h}$ and then embedded in paraffin. Paraffin sections $(4 \mu \mathrm{m})$ were dewaxed with xylene and rehydrated in ethanol according to a standard protocol. 
After that, the specimens were stained with hematoxylin and eosin (H\&E) followed by observation by bright-field microscopy. For immunohistochemical evaluation of mitophagy and cell proliferation, sections were stained with anti-Parkin and anti-Ki67 antibody $(1: 200,12202$, CST) respectively, then incubated with HRP-conjugated Goat anti-Rabbit IgG secondary antibody (1:200, 5220-0336, SeraCare, Shanghai) according to the manufacturer's instructions. The level of apoptosis of tumor sections in different treatment groups in was determined using the TUNEL method (11684817910, Roche Diagnostics).

Statistical analysis. All the experiments were conducted independently for three more times. All data was shown as mean \pm standard deviation (SD). Statistical analyses were performed by GraphPad Prism software version 7.0. Multiple comparisons were used by one-way or two-way ANOVA test. $P<0.05$ was statistically significant.

\section{Declarations}

\section{Ethics approval and consent to participate}

All animal care and experiments were performed in according with the guidelines approved by the Animal Ethics Committee of International Peace Maternity and Child Health Hospital, Shanghai Jiao Tong University School of Medicine.

\section{Consent for publication}

All authors consent for publication.

\section{Competing interests}

All authors declared no competing interests.

\section{Funding}

This study is supported by the Shanghai Municipal Key Clinical Specialty (No. shslczdzk06302), Shanghai Shenkang Hospital Development Center, Clinical Technology Innovation Project (No. SHDC12020130), "Science and Technology Innovation Action Plan" International Science and Technology Cooperation Project (No. 20550760600), National Natural Science Foundation of China (No. 81172477, 81402135), Shanghai Jiao Tong University Medicine-Engineering Fund (No. YG2017MS41), Shanghai Jiao Tong University School of Medicine, multi-center clinical research project (No. DLY201827) and Shanghai Municipal Science and Technology Commission.

\section{Authors' contributions}

Xiaodi Gong: investigation, methodology, data curation, validation, writing-original draft. Jing Wang: investigation, methodology, data curation, validation. Linlin Yang: Validation. Lijuan Li: Methodology, Supervision. Xiao Sun: Software. Jingfeng Bai: Methodology, Supervision, Resources. Jichang Liu: 
Conceptualization, Investigation, Methodology, Supervision, Writing-review and editing. Xin Pu:

Supervision, Writing-review and editing. Yudong Wang: Supervision, Writing-review and editing, Funding acquisition. All authors read and approved the final manuscript.

Xiaodi Gong and Jing Wang contributed equally to this work.

\section{Corresponding authors}

Xin Pu (xinpu9@hotmail.com),

Yudong Wang (wangyudong@shsmu.edu.cn)

\section{Availability of data and materials}

All data analyzed during this study are included in this published article and its additional file.

\section{Acknowledgments}

Not applicable.

\section{References}

1. V. Kasivisvanathan, A. S. Rannikko, M. Borghi, V. Panebianco, L. A. Mynderse, M. H. Vaarala, A.

Briganti, L. Budäus, G. Hellawell, R. G. Hindley, M. J. Roobol, S. Eggener, M. Ghei, A. Villers, F. Bladou, G. M. Villeirs, J. Virdi, S. Boxler, G. Robert, P. B. Singh, W. Venderink, B. A. Hadaschik, A. Ruffion, J. C. Hu, D. Margolis, S. Crouzet, L. Klotz, S. S. Taneja, P. Pinto, I. Gill, C. Allen, F. Giganti, A. Freeman, S. Morris, S. Punwani, N. R. Williams, C. Brew-Graves, J. Deeks, Y. Takwoingi, M. Emberton, C. M. Moore, N Engl J Med 2018, 378, 1767.

2. R. L. Siegel, K. D. Miller, H. E. Fuchs, A. Jemal, CA Cancer J Clin 2021, 71, 7.

3. J. Y. Park, J. H. Nam, Oncologist 2015, 20, 270.

4. A. A. Ciociola, L. B. Cohen, P. Kulkarni, Am J Gastroenterol 2014, 109, 620.

5. M. A. Clarke, S. S. Devesa, S. V. Harvey, N. Wentzensen, J Clin Oncol 2019, 37, 1895.

6. J. N. McAlpine, S. M. Temkin, H. J. Mackay, Cancer 2016, 122, 2787.

7. C. C. Winterbourn, Nat Chem Biol 2008, 4, 278.

8. D. Trachootham, J. Alexandre, P. Huang, Nat Rev Drug Discov 2009, 8, 579.

9. W. Fan, B. Yung, P. Huang, X. Chen, Chem Rev 2017, 117, 13566.

10. B. A. Webb, M. Chimenti, M. P. Jacobson, D. L. Barber, Nat Rev Cancer 2011, 11, 671.

11. R. A. Cairns, I. S. Harris, T. W. Mak, Nat Rev Cancer 2011, 11, 85.

12. L. S. Lin, J. Song, L. Song, K. Ke, Y. Liu, Z. Zhou, Z. Shen, J. Li, Z. Yang, W. Tang, G. Niu, H. H. Yang, X. Chen, Angew Chem Int Ed Engl 2018, 57, 4902. 
13. C. Zhang, W. Bu, D. Ni, S. Zhang, Q. Li, Z. Yao, J. Zhang, H. Yao, Z. Wang, J. Shi, Angew Chem Int Ed Engl 2016, 55, 2101.

14. B. W. Yang, Y. Chen, J. L. Shi, Progress in Biochemistry and Biophysics 2018, 45, 237.

15. L. Gao, J. Zhuang, L. Nie, J. Zhang, Y. Zhang, N. Gu, T. Wang, J. Feng, D. Yang, S. Perrett, X. Yan, Nat Nanotechnol 2007, 2, 577.

16. D. M. Huang, J. K. Hsiao, Y. C. Chen, L. Y. Chien, M. Yao, Y. K. Chen, B. S. Ko, S. C. Hsu, L. A. Tai, H. Y. Cheng, S. W. Wang, C. S. Yang, Y. C. Chen, Biomaterials 2009, 30, 3645.

17. Q. Chang, K. Deng, L. Zhu, G. Jiang, C. Yu, H. Tang, Microchimica Acta 2009, 165, 299.

18. Z. Chen, J. J. Yin, Y. T. Zhou, Y. Zhang, L. Song, M. Song, S. Hu, N. Gu, ACS Nano 2012, 6, 4001.

19. B. Yang, L. Ding, H. Yao, Y. Chen, J. Shi, Adv Mater 2020, 32, e1907152.

20. T. P. Szatrowski, C. F. Nathan, Cancer Res 1991, 51, 794.

21. S. C. Gupta, D. Hevia, S. Patchva, B. Park, W. Koh, B. B. Aggarwal, Antioxid Redox Signal 2012, 16, 1295.

22. H. Ranji-Burachaloo, A. Reyhani, P. A. Gurr, D. E. Dunstan, G. G. Qiao, Nanoscale 2019, 11, 5705.

23. L. S. Lin, T. Huang, J. Song, X. Y. Ou, Z. Wang, H. Deng, R. Tian, Y. Liu, J. F. Wang, Y. Liu, G. Yu, Z. Zhou, S. Wang, G. Niu, H. H. Yang, X. Chen, J Am Chem Soc 2019, 141, 9937.

24. R. Li, M. A. Bianchet, P. Talalay, L. M. Amzel, Proc Natl Acad Sci U S A 1995, 92, 8846.

25. E. T. Oh, J. W. Kim, J. M. Kim, S. J. Kim, J. S. Lee, S. S. Hong, J. Goodwin, R. J. Ruthenborg, M. G. Jung, H. J. Lee, C. H. Lee, E. S. Park, C. Kim, H. J. Park, Nat Commun 2016, 7, 13593.

26. X. Huang, E. A. Motea, Z. R. Moore, J. Yao, Y. Dong, G. Chakrabarti, J. A. Kilgore, M. A. Silvers, P. L. Patidar, A. Cholka, F. Fattah, Y. Cha, G. G. Anderson, R. Kusko, M. Peyton, J. Yan, X. J. Xie, V. Sarode, N. S. Williams, J. D. Minna, M. Beg, D. E. Gerber, E. A. Bey, D. A. Boothman, Cancer Cell 2016, 30, 940.

27. J. J. Pink, S. M. Planchon, C. Tagliarino, M. E. Varnes, D. Siegel, D. A. Boothman, J Biol Chem 2000, $275,5416$.

28. C. M. Doskey, V. Buranasudja, B. A. Wagner, J. G. Wilkes, J. Du, J. J. Cullen, G. R. Buettner, Redox Biol 2016, 10, 274.

29. X. Gong, X. Pu, J. Wang, L. Yang, Y. Cui, L. Li, X. Sun, J. Liu, J. Bai, Y. Wang, Int J Nanomedicine 2021, $16,6661$.

30. M. S. Bentle, E. A. Bey, Y. Dong, K. E. Reinicke, D. A. Boothman, J Mol Histol 2006, 37, 203.

31. X. Huang, Y. Dong, E. A. Bey, J. A. Kilgore, J. S. Bair, L. S. Li, M. Patel, E. I. Parkinson, Y. Wang, N. S. Williams, J. Gao, P. J. Hergenrother, D. A. Boothman, Cancer Res 2012, 72, 3038.

32. E. A. Bey, M. S. Bentle, K. E. Reinicke, Y. Dong, C. R. Yang, L. Girard, J. D. Minna, W. G. Bornmann, J. Gao, D. A. Boothman, Proc Natl Acad Sci U S A 2007, 104, 11832.

33. W. X. Zong, D. Ditsworth, D. E. Bauer, Z. Q. Wang, C. B. Thompson, Genes Dev 2004, 18, 1272.

34. J. J. Pink, S. Wuerzberger-Davis, C. Tagliarino, S. M. Planchon, X. Yang, C. J. Froelich, D. A. Boothman, Exp Cell Res 2000, 255, 144. 
35. S. W. Yu, H. Wang, M. F. Poitras, C. Coombs, W. J. Bowers, H. J. Federoff, G. G. Poirier, T. M. Dawson, V. L. Dawson, Science 2002, 297, 259.

36. D. E. Gerber, M. S. Beg, F. Fattah, A. E. Frankel, O. Fatunde, Y. Arriaga, J. E. Dowell, A. Bisen, R. D. Leff, C. C. Meek, W. C. Putnam, R. R. Kallem, I. Subramaniyan, Y. Dong, J. Bolluyt, V. Sarode, X. Luo, Y. Xie, B. Schwartz, D. A. Boothman, Br J Cancer 2018, 119, 928.

37. G. Chakrabarti, Z. R. Moore, X. Luo, M. Ilcheva, A. Ali, M. Padanad, Y. Zhou, Y. Xie, S. Burma, P. P. Scaglioni, L. C. Cantley, R. J. DeBerardinis, A. C. Kimmelman, C. A. Lyssiotis, D. A. Boothman, Cancer Metab 2015, 3, 12.

38. L. Zhang, Z. Chen, K. Yang, C. Liu, J. Gao, F. Qian, Mol Pharm 2015, 12, 3999.

39. Z. Moore, G. Chakrabarti, X. Luo, A. Ali, Z. Hu, F. J. Fattah, R. Vemireddy, R. J. DeBerardinis, R. A. Brekken, D. A. Boothman, Cell Death Dis 2015, 6, e1599.

40. G. R. Buettner, Arch Biochem Biophys 1993, 300, 535.

41. X. Ma, X. Huang, Z. Moore, G. Huang, J. A. Kilgore, Y. Wang, S. Hammer, N. S. Williams, D. A. Boothman, J. Gao, J Control Release 2015, 200, 201.

42. Y. Dong, S. F. Chin, E. Blanco, E. A. Bey, W. Kabbani, X. J. Xie, W. G. Bornmann, D. A. Boothman, J. Gao, Clin Cancer Res 2009, 15, 131.

43. E. Ruoslahti, Annu Rev Cell Dev Biol 1996, 12, 697.

44. J. D. Hood, D. A. Cheresh, Nat Rev Cancer 2002, 2, 91.

45. J. P. Xiong, T. Stehle, R. Zhang, A. Joachimiak, M. Frech, S. L. Goodman, M. A. Arnaout, Science 2002, $296,151$.

46. Y. Ye, S. Bloch, B. Xu, S. Achilefu, J Med Chem 2006, 49, 2268.

47. B. D'Autréaux, M. B. Toledano, Nat Rev Mol Cell Biol 2007, 8, 813.

48. Y. Kabeya, N. Mizushima, T. Ueno, A. Yamamoto, T. Kirisako, T. Noda, E. Kominami, Y. Ohsumi, T. Yoshimori, Embo j 2000, 19, 5720.

\section{Schema}

Schema file is available in supplementary section

\section{Figures}



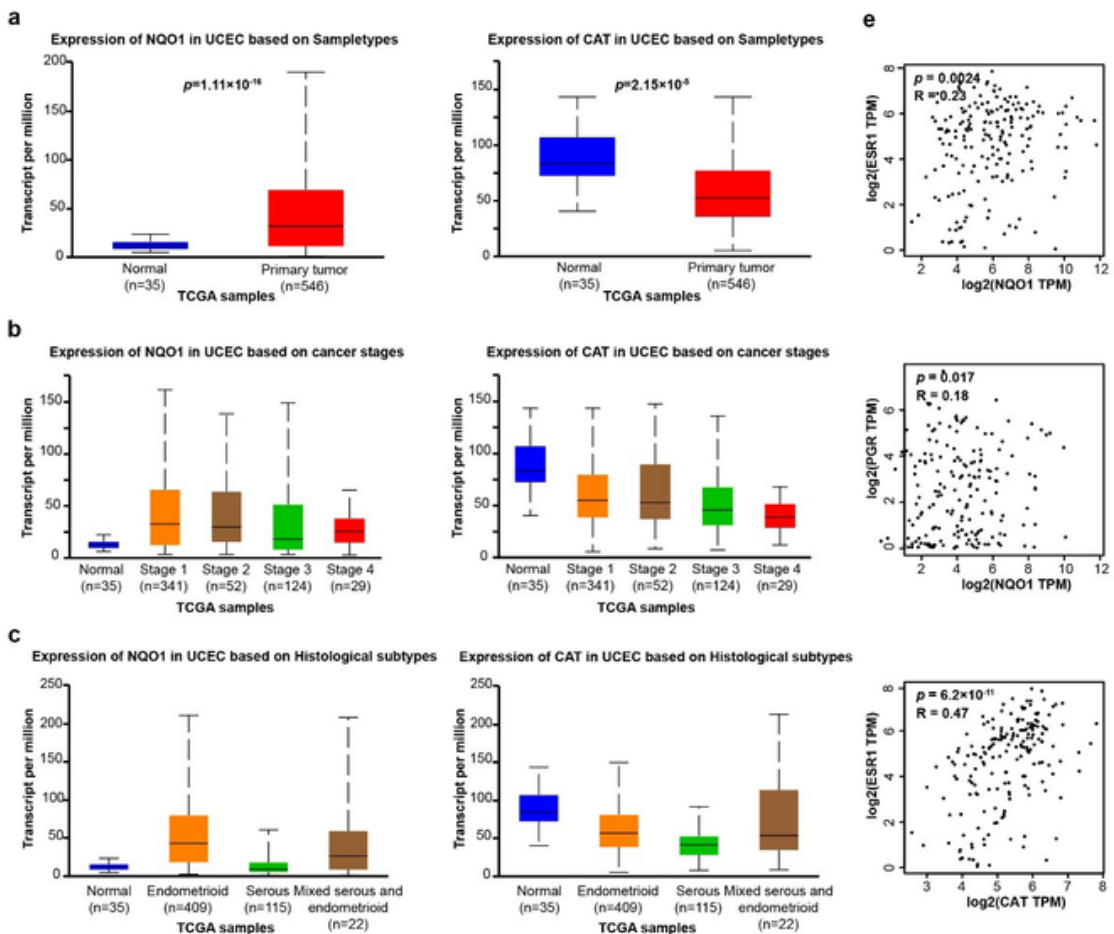

d
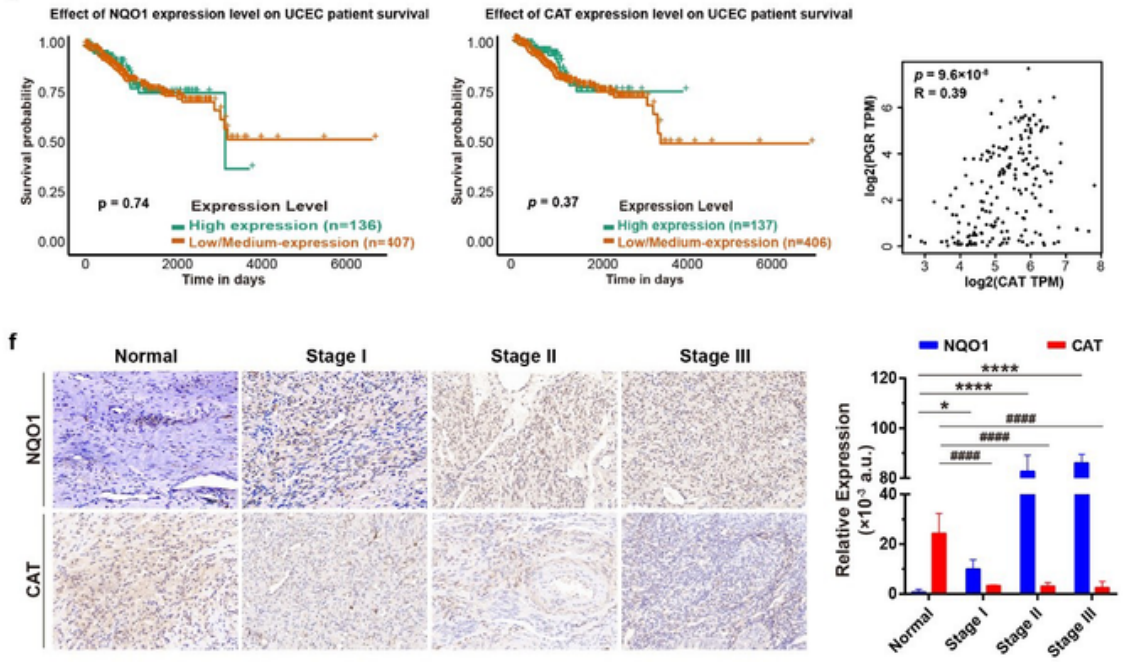

g
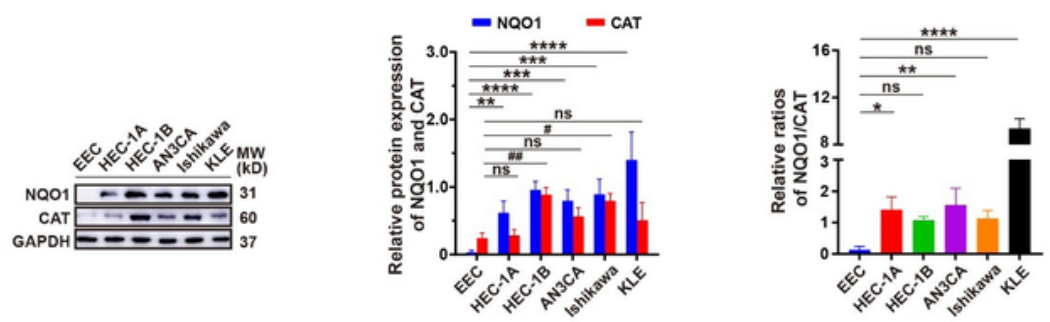

\section{Figure 1}

The expression of NQ01 and CAT in Uterine Corpus Endometrial Carcinoma (UCEC). (a) Boxplots showed NQ01 and CAT mRNA differential expression in a panel of normal $(n=35)$ and tumor samples $(n=546)$ from the TCGA databases and the levels of both in UCEC samples were categorized by disease stages. (b) and histological subtypes. (c). In each group, median expression levels were indicated by horizontal lines within boxplots and also the number of samples were shown at the bottom of the corresponding 
boxplot. (d) Correlation between NQ01, CAT mRNA and ESR, PGR mRNA expression respectively within UCEC datasets. The Spearman's correlation coefficient (R) and $p$-value were shown in each plot. (e) Overall survival of UCEC patients separated by high vs. low NQ01, CAT mRNA. The corresponding $p$ values were shown in each figure. (f) Immunohistochemical analysis of NQ01 and CAT expression in human endometrial cancer tissues of different clinical stages (I, II, III) and normal endometrium tissues. (g) Immunoblots illustrating the basal expression of NQO1 and CAT in the indicated human EC cell lines and human normal endometrial epithelial cells (EEC). GAPDH served as an internal reference for normalization. Data are shown as mean \pm SEM from three independent experiments. ${ }^{\star} p<0.05,{ }^{\star} * p<0.01$, $\star \star \star p<0.005, * \star \star \star x<0.0001, \# p<0.05, \# \# p<0.01, \# \# \# \#<<0.0001$, and ns: not significant determined by one way ANOVA in (g) or two-way ANOVA in $(\mathrm{g}, \mathrm{f})$. 
a

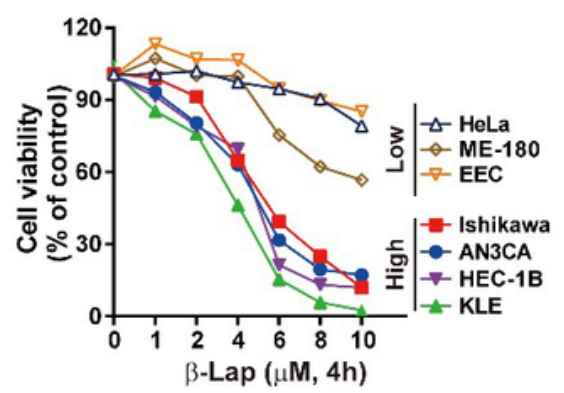

d

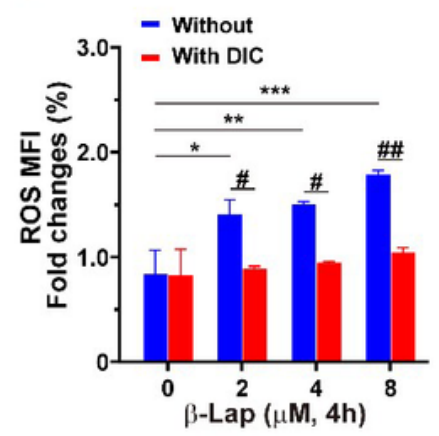

9

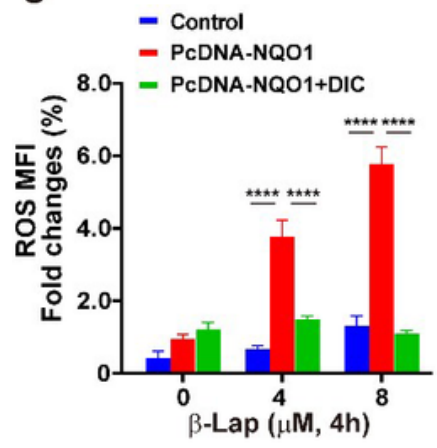

j

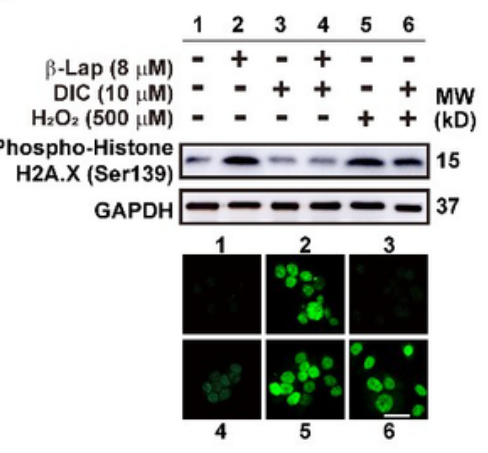

b

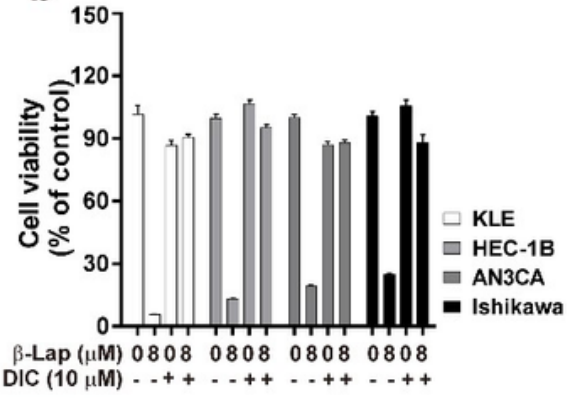

C
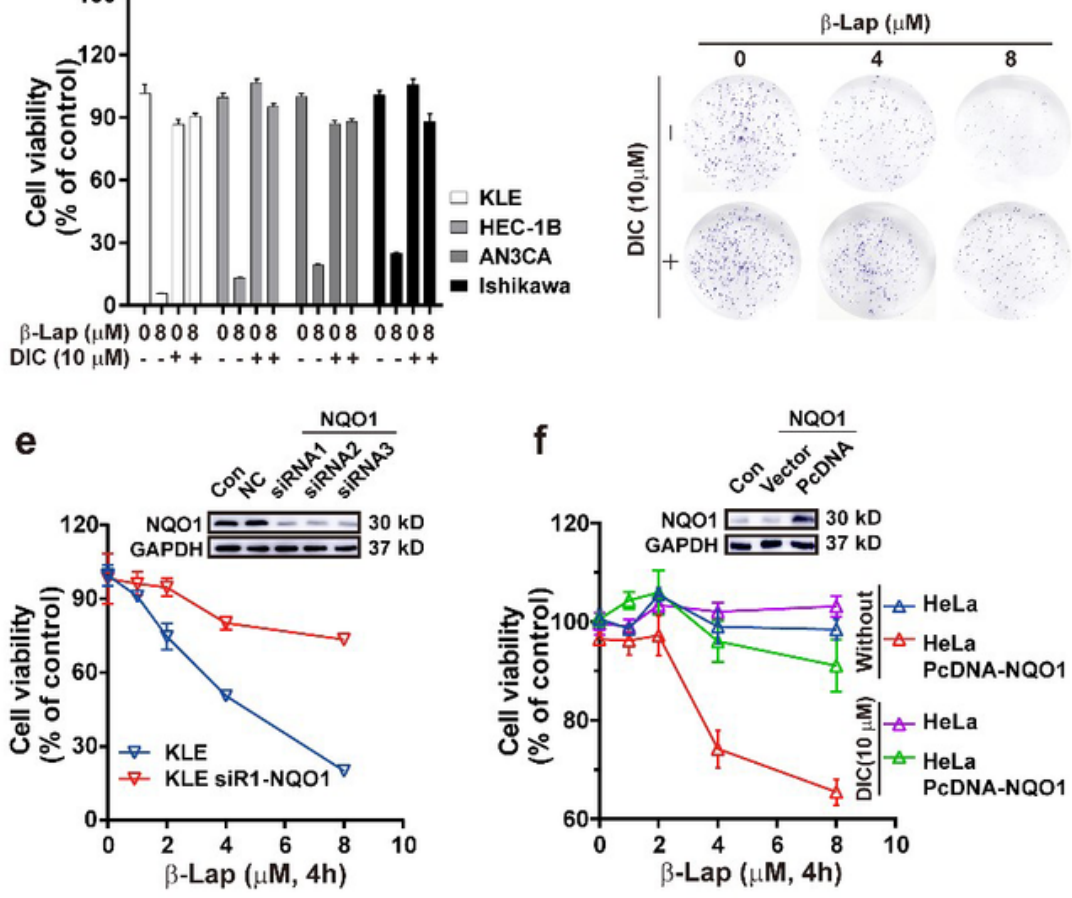

h

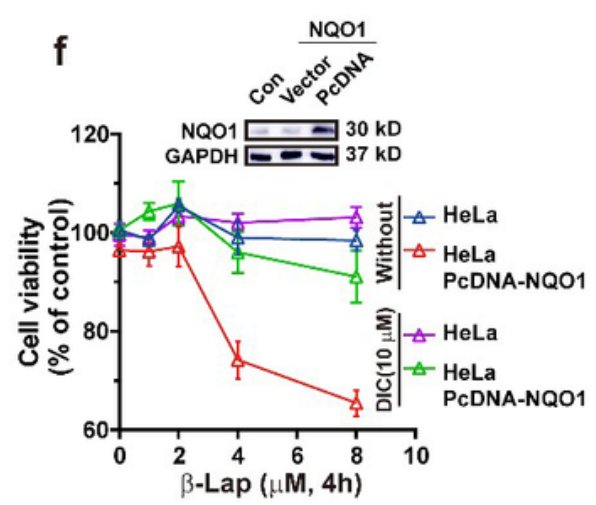

i

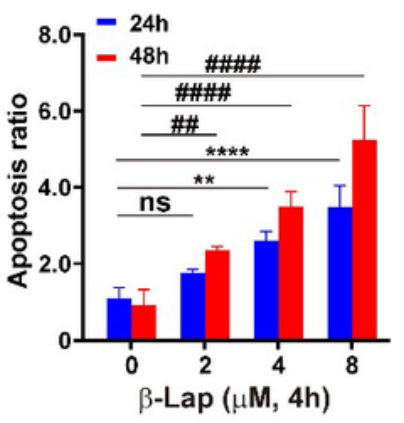

k

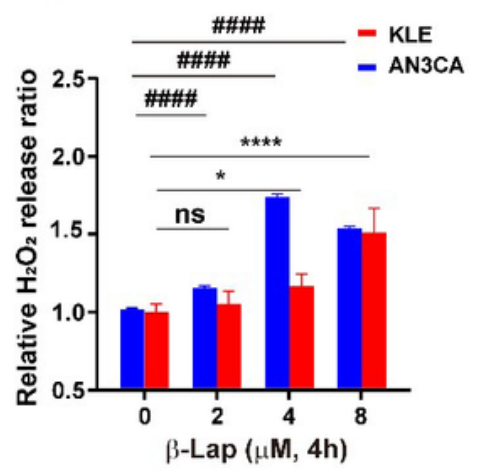

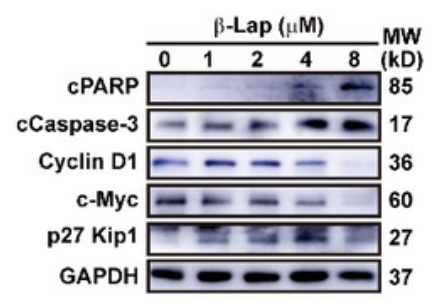

I

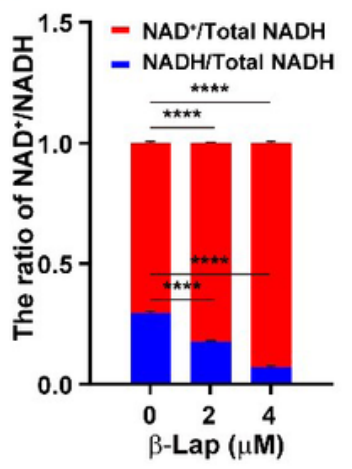

Figure 2

$\beta$-Lap selectively inhibited the growth of $\mathrm{NQO}^{\text {high }}$ cells.

(a) Cell viability of NQ01 high (Ishikawa, AN3CA, HEC-1B and KLE) and NQ01 low (HeLa, ME-180 and EEC) cells were assayed separately after $\beta$-Lap $(0$ to $10 \mathrm{mM}, 4 \mathrm{~h})$ addition for $48 \mathrm{~h}$. (b) Ishikawa, ANC3A, HEC$1 \mathrm{~B}$ and KLE cells were exposed to $8 \mu \mathrm{M} \beta$-Lap $\pm 10 \mu \mathrm{M}$ Dicoumarol (DIC) for $4 \mathrm{~h}$ and cell viability was 
analyzed after $48 \mathrm{~h}$ of treatment, respectively. The colony-forming ability of KLE cells was also determined (c). (d) After $4 \mathrm{~h}$ exposure in (0 to 8mM) $\beta$-Lap $\pm 10 \mu \mathrm{M} \mathrm{DIC}$, the ROS levels in KLE cells were measured by DCFH-DA fluorescence. (e) KLE cells transfected with siRNA-1(siR-1) NQ01 were exposed to (0-8 mM) $\beta$-Lap for $4 \mathrm{~h}$ and cell viability was assessed $48 \mathrm{~h}$ later. Immunoblots showed siRNA-1, $-2,-3$ NQ01 and negative control (NC) siRNA transfection efficiency (upper right, inset). (f) HeLa cells transfected with pcDNA-NQ01 plasmids were treated with $\beta$-Lap $\pm 10 \mu \mathrm{M}$ DIC for $4 \mathrm{~h}$. Cell survival, intracellular ROS levels $(\mathrm{g})$ were assessed $48 \mathrm{~h}$ later. Overexpression efficiencies of pcDNA-NQO1 or empty vector control were tested by immunoblots (upper right, inset). (h) The percentages of KLE apoptotic cells were determined by flow cytometry $24 \mathrm{~h}$ and $48 \mathrm{~h}$ after $\beta$-Lap stimulation ( 0 to $8 \mathrm{mM}, 4 \mathrm{~h}$ ). (i) The protein expression levels of cleaved PARP (cPARP), cleaved Caspase-3 (cCaspase-3), Cyclin D1, c-Myc and p27 Kip1 of KLE cells $48 \mathrm{~h}$ after $\beta$-Lap addition ( 0 to $8 \mathrm{mM}, 4 \mathrm{~h}$ ) were evaluated by immunoblots. GAPDH was used as a loading control. (j) The Phospho-Histone H2A.X (Ser139) expression of KLE cells was detected by immunoblots and immunofluorescence $48 \mathrm{~h}$ after different exposures (scale bar was $50 \mu \mathrm{m}$ ). 1: control; 2: $\beta$-Lap (8 mM, 4 h); 3: DIC $\left(10 \mu \mathrm{M}, 4\right.$ h); 4: $\beta$-Lap (8 mM, 4 h) + DIC $\left(10 \mu M, 4\right.$ h); $5: \mathrm{H}_{2} \mathrm{O}_{2}(500$ $\mathrm{mM}, 15 \mathrm{~min}) ; 6: \mathrm{H}_{2} \mathrm{O}_{2}(500 \mathrm{mM}, 15 \mathrm{~min})+\mathrm{DIC}(10 \mathrm{mM}, 15 \mathrm{~min})$. (k) The effects of $\beta$-Lap (0 to $\left.8 \mathrm{mM}, 4 \mathrm{~h}\right)$ on $\mathrm{H}_{2} \mathrm{O}_{2}$ release in AN3CA and KLE cells, respectively. (I) The NAD ${ }^{+} / \mathrm{NADH}$ ratio in KLE cells $48 \mathrm{~h}$ after $\beta$ Lap treatment ( 0 to $4 \mathrm{mM}, 4 \mathrm{~h}$ ). Data are shown as mean \pm SEM from three independent experiments.

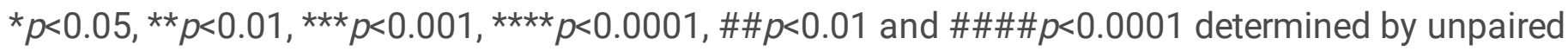
Student's t-test or two-way ANOVA. 


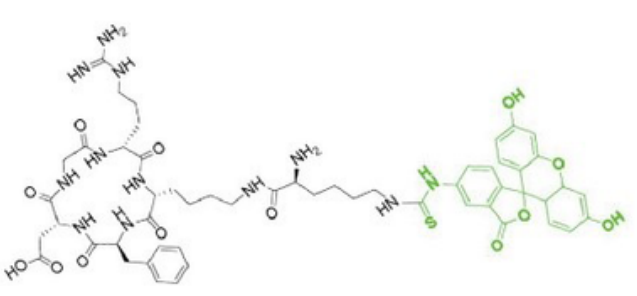

Cyclo(RGDfK(K(FITC)

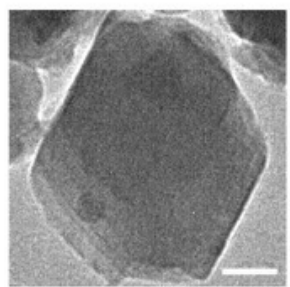

nMIL-100(Fe)

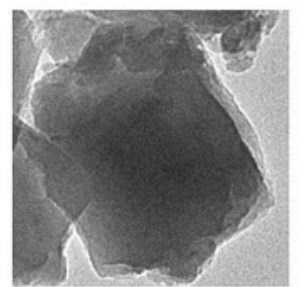

RGD-nMIL-100(Fe) c

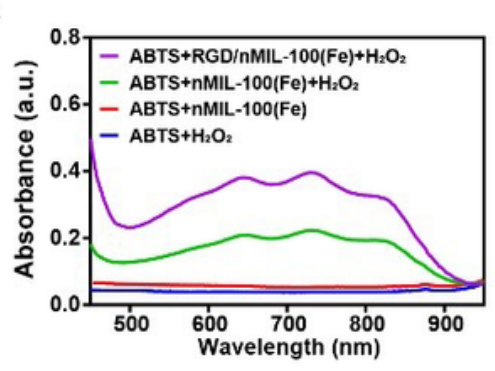

f

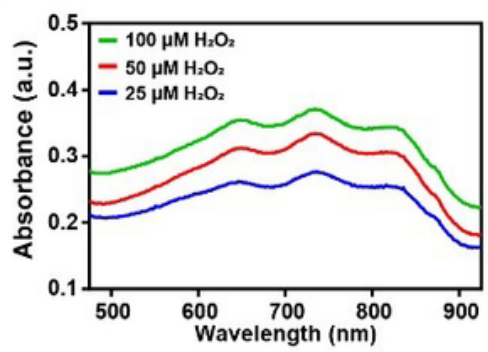

d

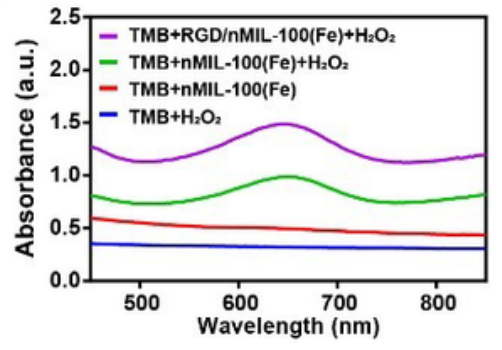

g

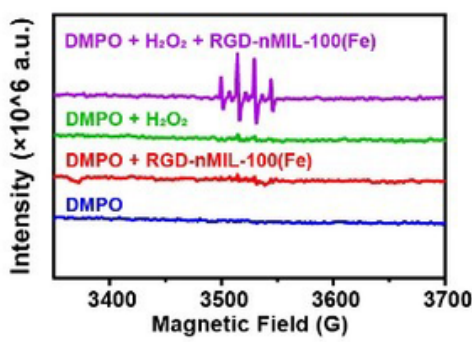

e
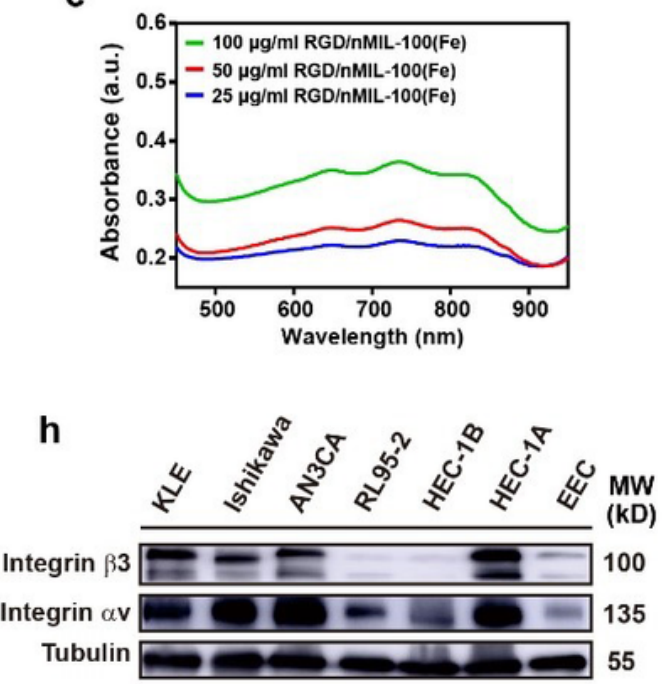

i

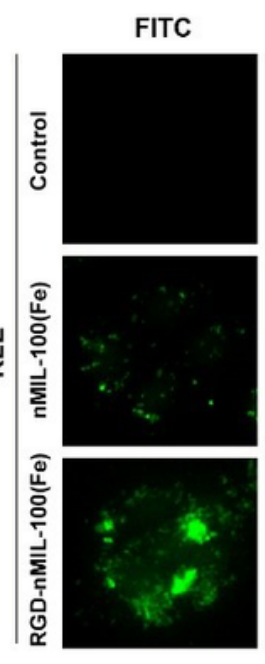

Hoechst
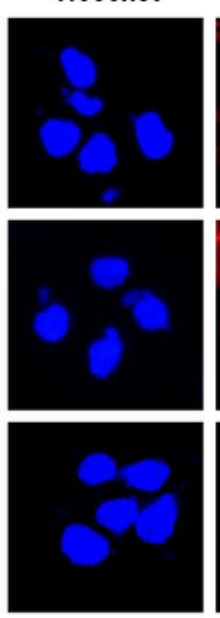
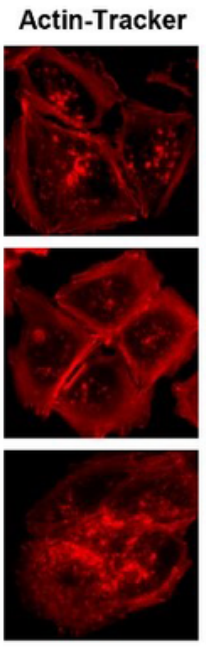
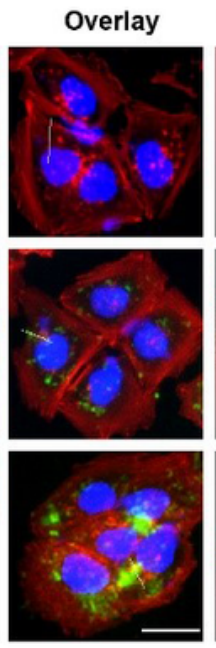
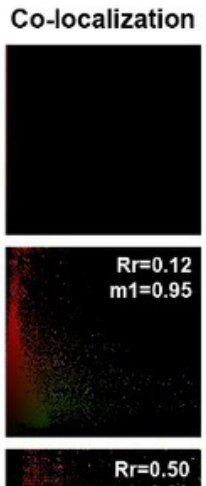

$\mathrm{R} r=0.50$
$\mathrm{~m} 1=0.98$

$\mathrm{m} 1=0.98$

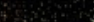

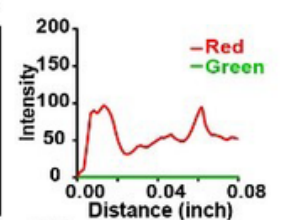

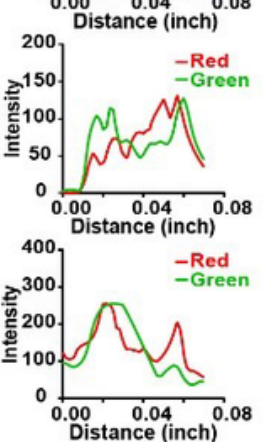

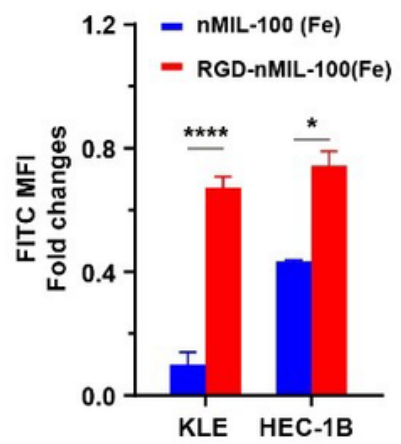

Figure 3

The characterization and cellular internalization of RGD-nMIL-100(Fe)

(a) Structure diagram of Cyclo(RGDfK(K(FITC) peptide. (b) TEM images of the nMIL-100(Fe) and RGDnMIL-100(Fe) nanoparticles (scale bar is $50 \mathrm{~nm}$ ). (c-d) UV-vis absorption spectra of ABTS and TMB at 500-900 nm and $652 \mathrm{~nm}$ of different groups, respectively. (e-f) Effect of RGD-nMIL-100(Fe) or $\mathrm{H}_{2} \mathrm{O}_{2}$ 
concentrations on absorbance of ABTS at $500-900 \mathrm{~nm}$. (g) ESR spectra of $\cdot \mathrm{OH}$ adducts were determined. (h) Immunoblots illustrating the basal expression of Integrin $\beta 3$ and Integrin av in the indicated EC cell lines and EEC cells, respectively. Tubulin was used as a loading control. (i) Confocal fluorescence images of KLE cells incubated with FITC-labeled nMIL-100(Fe) and RGD-nMIL-100(Fe) nanoparticles for $6 \mathrm{~h}$, displaying nanoparticles internalization (green channel), cell actin (red channel) and nucleus (blue channel) staining (scale bar was $10 \mu \mathrm{m}$ ). The co-localization relations were analyzed by Plot Profile plugin and Pearson's coefficient (Rr) and Manders' overlap coefficient (M1) were labeled in the top right corner of the co-localization channels, respectively. The MFI of FITC in KLE and HEC-1B cells were also analyzed. Data were represented as mean $\pm S D(n=3)$. ${ }^{\star} p<0.05$, ${ }^{\star \star \star \star} p<0.0001$ determined by two-way ANOVA. TMB $1.0 \times 10^{-3} \mathrm{M}$, ABTS $0.2 \times 10^{-3} \mathrm{M}$, nMIL-100(Fe) and RGD-nMIL-100(Fe) $\times 100 \mathrm{mg} \mathrm{ml}^{-1}, \mathrm{H}_{2} \mathrm{O}_{2}$ $100 \times 10^{-6} \mathrm{M}$, DMPO $50 \times 10^{-3} \mathrm{M}$ and $\mathrm{MFI}$ : mean fluorescence intensity. 
a

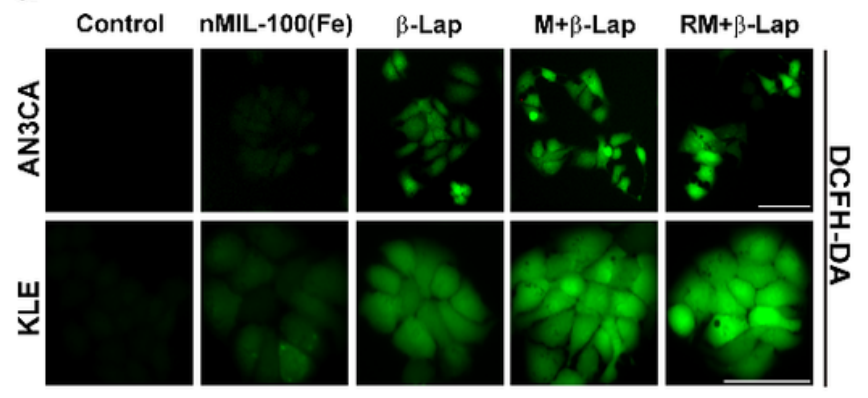

C

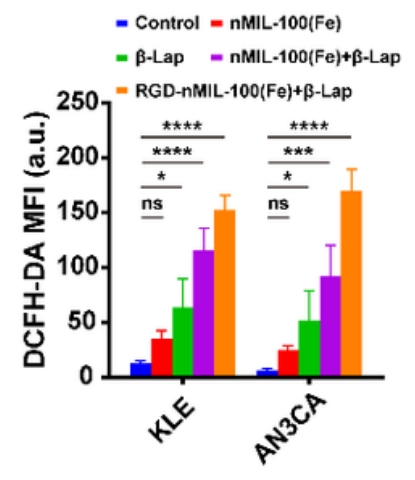

e
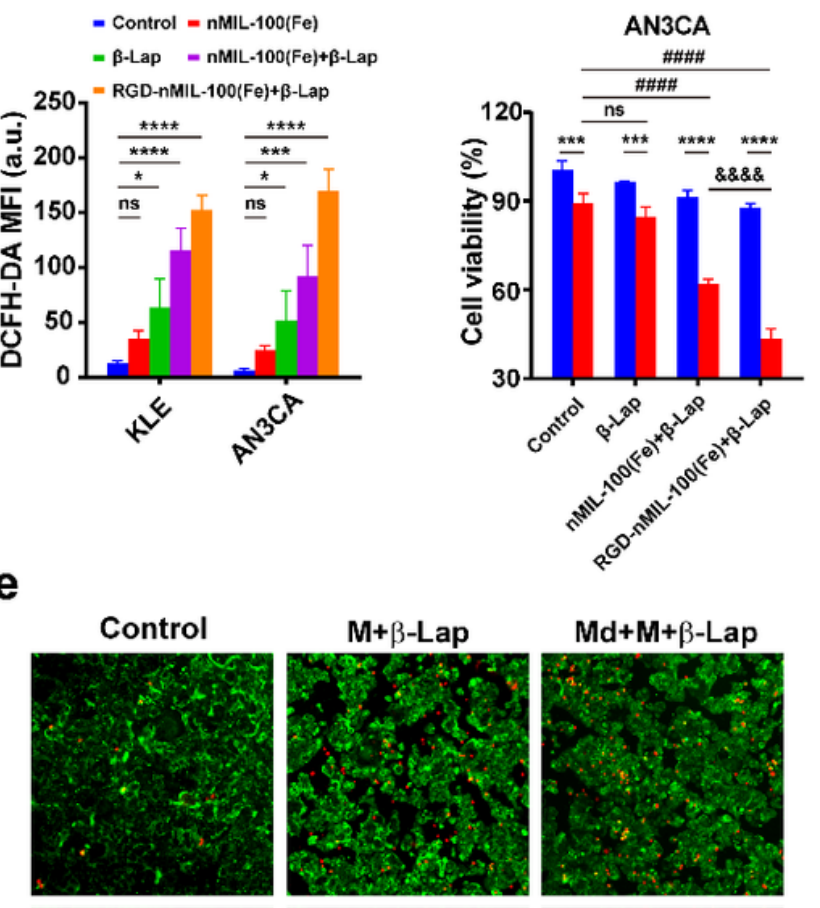

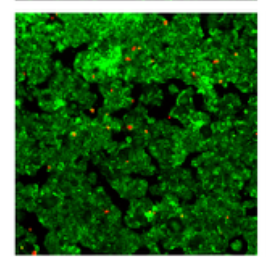

$\beta$-Lap

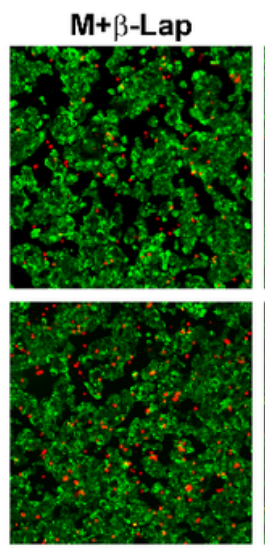

$R M+\beta-$ Lap
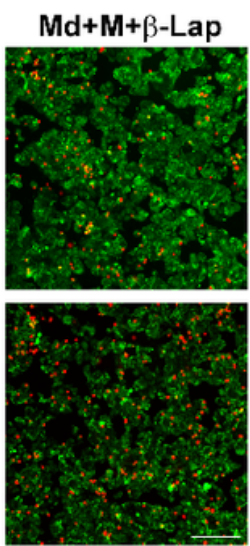

$M d+R M+\beta-$ Lap

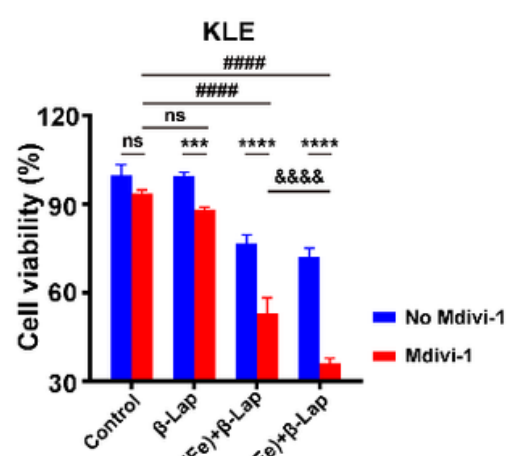

d

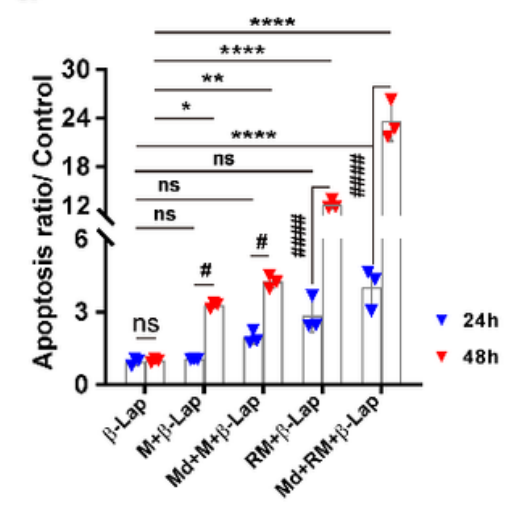

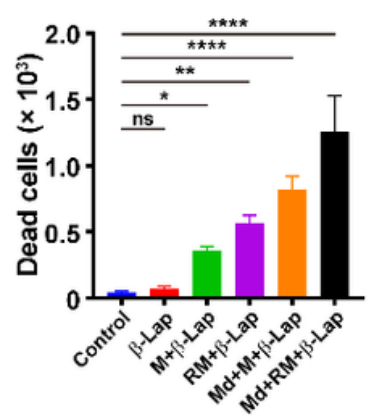

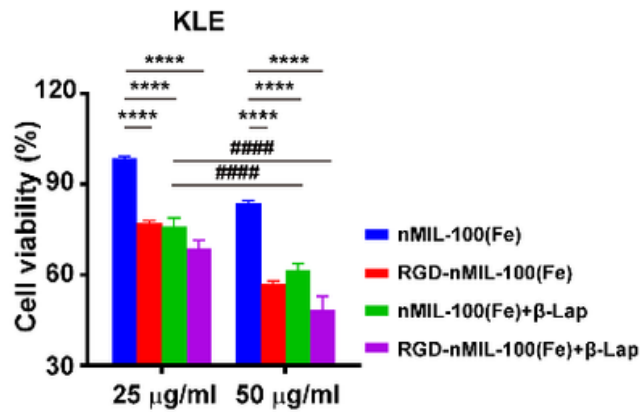

$\mathbf{f}$

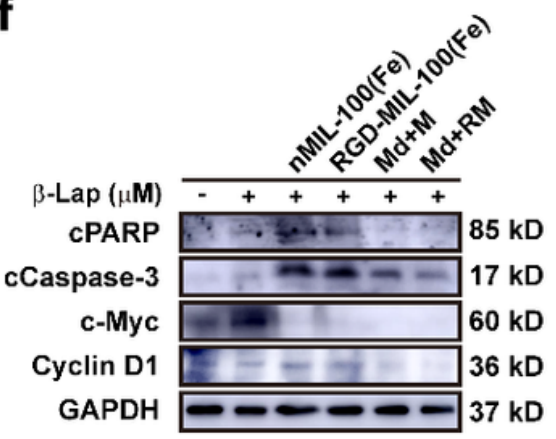

Figure 4

The enhanced anticancer efficacy of $\beta$-Lap combined with RGD-nMIL-100(Fe) and Mdivi-1 in NQO1 ${ }^{\text {high }}$ CAT ${ }^{\text {low }}$ EC cell lines.

(a) The ROS production of treated AN3CA and KLE cells were measured using fluorescent probe DCFHDA. Bar graph showed mean fluorescence intensities (MFI) in each group (control, nMIL-100(Fe) $25 \mathrm{\mu g} \mathrm{ml}^{-}$ 1, $\beta$-Lap $2.0 \times 10^{-6} \mathrm{M}, \mathrm{M}+\beta$-Lap: nMIL-100(Fe) $25 \mathrm{\mu g} \mathrm{ml}^{-1}+\beta$-Lap 2.0×10-6 $\mathrm{M}$ and RM+ $\beta$-Lap: RGD-nMIL100(Fe) $25 \mu \mathrm{g} \mathrm{ml}^{-1}+\beta$-Lap $2.0 \times 10^{-6} \mathrm{M}$. scale bars were $20 \mu \mathrm{m}$ ). (b) Cell viability of AN3CA and KLE cells after incubation with different concentrations $\left(25 \mathrm{\mu g} \mathrm{ml}^{-1}, 50 \mathrm{\mu g} \mathrm{ml}^{-1}\right)$ of nMIL-100(Fe) and RGD-nMIL$100(\mathrm{Fe})$ and the combination of the two with $2.0 \times 10^{-6} \mathrm{M}$ B-Lap) for $48 \mathrm{~h}$. (c) Effect of different treatment 
combinations including nMIL-100(Fe) (12.5 $\left.\mathrm{g} \mathrm{m} \mathrm{ml}^{-1}, 48 \mathrm{~h}\right), \mathrm{RGD}-\mathrm{nMIL}-100(\mathrm{Fe})\left(12.5 \mu \mathrm{g} \mathrm{ml}^{-1}, 48 \mathrm{~h}\right), \beta$-Lap $\left(1.0 \times 10^{-6} \mathrm{M}, 4 \mathrm{~h}\right)$ and the Mdivi- $1\left(10 \times 10^{-6} \mathrm{M}, 1 \mathrm{~h}\right)$ pretreatment on KLE and AN3CA cell viability. (d) Histograms represented the percentages of KLE apoptotic cells determined by flow cytometry $24 \mathrm{~h}$ and 48 $\mathrm{h}$ after different stimulations as aforementioned (c). (e) The images of KLE cells suffered the treatments as (c) for $48 \mathrm{~h}$ (scale bar was $200 \mu \mathrm{m}$ ). The number of dead cells (red fluorescence) was calculated. Md: Mdivi-1. (f) Immunoblots illustrating changes in the expression of cPARP, cCaspase-3, c-Myc and Cyclin D1 in response to various interventions for $48 \mathrm{~h}$. The GAPDH was used as an internal control. Data are shown as mean \pm SD from three independent experiments. ${ }^{\star} p<0.05,{ }^{*} p<0.01,{ }^{* \star *} p<0.001,{ }^{* \star * \star} p<0.0001$,

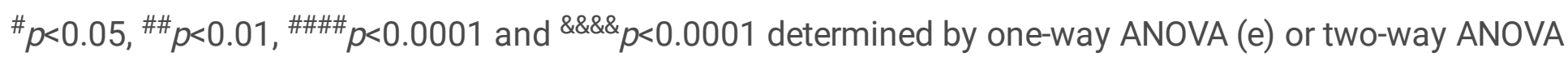
$(a-d)$. 
a
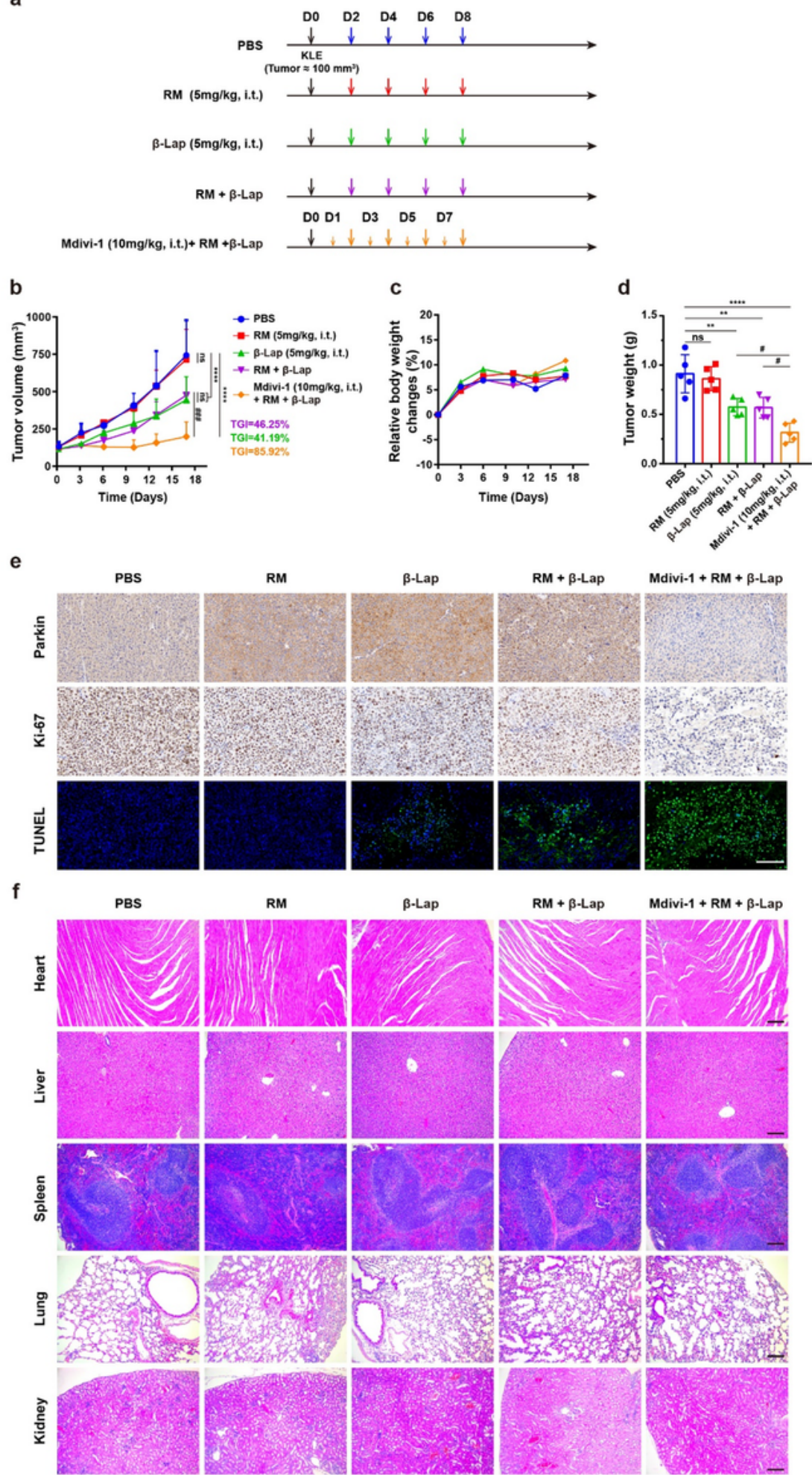

\section{Figure 5}

The synergistic antitumor therapeutic efficacy of $\operatorname{MOF}(\mathrm{Fe}) / \beta$-Lap in vivo. KLE tumor xenografts mice treated with PBS, MOFs, $\beta$-Lap, synergistic therapy and Mdivi-1 pretreatment together with the synergistic therapy every other day for four times. (a) Schematic of the treatment regimen for KLE tumor-bearing mice. D: Day. (b) The average tumor volume and (c) relative body weights were recorded and plotted as a function of time. (d) Quantification of KLE tumors weights 17 days after treatment. (e) 
Immunohistochemical analysis of Parkin, Ki 67 and TUNEL staining in harvested KLE tumor tissues on day 17 after treatments (scale bars were $100 \mu \mathrm{m}$ ). (f) Histology assessment of major organs (heart, liver, spleen, lung and kidney) collected from each group-treated mice at experimental endpoint (scale bars were $100 \mu \mathrm{m})$. Data are shown as mean \pm SEM from three independent experiments. ${ }^{\star \star} p<0.01$, $\star \star \star x<0.001,{ }^{* \star \star \star} p<0.0001, \# \# \# p<0.001$ determined by Ordinary one-way in $(\mathrm{b}, \mathrm{d})$ or two-way ANOVA in (b).

\section{Supplementary Files}

This is a list of supplementary files associated with this preprint. Click to download.

- Supplementaryfile.docx

- schema.docx 